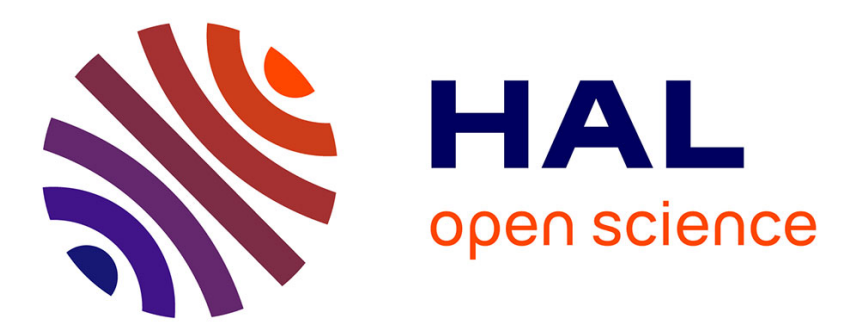

\title{
Neuro-cognitive correlates of alexithymia in patients with circumscribed prefrontal cortex damage
}

Ouerchefani Riadh, Ouerchefani Naoufel, Mohamed Riadh Ben Rejeb, Didier

Le Gall

\section{- To cite this version:}

Ouerchefani Riadh, Ouerchefani Naoufel, Mohamed Riadh Ben Rejeb, Didier Le Gall. Neuro-cognitive correlates of alexithymia in patients with circumscribed prefrontal cortex damage. Neuropsychologia, 2019, 135, pp.107228 -. 10.1016/j.neuropsychologia.2019.107228 . hal-03488500

\section{HAL Id: hal-03488500 https://hal.science/hal-03488500}

Submitted on 21 Dec 2021

HAL is a multi-disciplinary open access archive for the deposit and dissemination of scientific research documents, whether they are published or not. The documents may come from teaching and research institutions in France or abroad, or from public or private research centers.
L'archive ouverte pluridisciplinaire HAL, est destinée au dépôt et à la diffusion de documents scientifiques de niveau recherche, publiés ou non, émanant des établissements d'enseignement et de recherche français ou étrangers, des laboratoires publics ou privés.

\section{(ㄷ)(1) $\$$}

Distributed under a Creative Commons Attribution - NonCommercial| 4.0 International 


\section{Neuro-cognitive correlates of alexithymia in patients with circumscribed prefrontal cortex damage}

\section{Ouerchefani Riadh ${ }^{1,2}$}

1. University of Tunis El Manar, High Institute of Human sciences, 26 Boulevard Darghouth Pacha, Tunis, Tunisia.

2. Laboratory of Psychology of Pays de la Loire (EA 4638), France.

Phone Number : 0021697695358

Mail:werchefani.riadh@laposte.net

\section{Ouerchefani Naoufel ${ }^{3}$}

Department of Neurosurgery, Foch Hospital

40 Rue Worth, 92151 Suresnes

Phone Number: 0033614957970

Mail: naoufelour@yahoo.fr

\section{Mohamed Riadh Ben Rejeb ${ }^{4}$}

Faculty of Human and Social Science of Tunisia, Boulvard 9 Avril, C.P. 1007, Tunis, Tunisia Phone Number : 0021698469766

Mail: riadhbenrejeb@yahoo.fr 


\section{Didier Le Gall ${ }^{2}$}

University of Angers, Laboratory of Psychology of Pays de la Loire (EA 4638), 5 bis, boulevard Lavoisier, 49045 Angers cedex 01, France

Phone Number: 003360817088

Mail: DiLeGall@chu-angers.fr 


\title{
Neuro-cognitive correlates of alexithymia in patients with circumscribed
}

\section{prefrontal cortex damage}

\begin{abstract}
Alexithymia has been extensively reported in studies of psychiatric patients. However, little attention has been paid regarding its occurrence in the context of patients with circumscribed prefrontal cortex lesions. Moreover, the neuro-cognitive impairments that lead to alexithymia remain unclear and limited numbers of studies have addressed these issues. The authors investigated the impact of prefrontal cortex lesions on alexithymia and its neuro-cognitive correlates in a population of 20 patients with focal frontal lesions, 10 patients with parietal lesions and 34 matched control participants. Alexithymia was screened using the Toronto Alexithymia Scale (TAS-20) and executive functions were assessed using a large battery of executive tasks that address inhibition, flexibility and the planning process. Results showed that patients with prefrontal cortex damage showed significantly increased difficulty in facets of identifying feelings (DIF) and externally oriented thinking (EOT) on TAS-20, compared to parietal patients and control participants. Moreover, both correlation and regression analysis revealed that higher alexithymia levels on the three facets of TAS-20 were consistently but differentially associated with impairment in inhibition, flexibility and planning tasks for frontal patients and both control groups. These findings provide clinical evidence of the implication of prefrontal cortex damage and executive control in alexithymia. Our results were also discussed in the light of the cognitive appraisal concept as a mechanism involved in emotion episode processing. This study suggests that increased neuropsychological attention should be directed to the relation between the neuro-cognitive model of executive functions and cognitive appraisal theory in processing emotion.
\end{abstract}

Key words: Alexithymia, executive functions, cognitive appraisal, prefrontal cortex. 


\section{Introduction}

Alexithymia is a cognitive-affective disturbance characterized by difficulties in identifying, differentiating and communicating one's own emotional state and personal feelings (Sifneos, 1973; Taylor et al., 1997). The core feature of alexithymia is the inability to symbolize or mentalize emotions. Specifically, emotions are not cognitively elaborated by mental imaging or by words. This term was originally used to describe patients with psychosomatic disorders whose symptoms were thought to result from an impoverished emotional life and restricted verbalization of affect (Sifneos, Apfel-Savitz, \& Frankel, 1977). However, according to some authors, alexithymia is also conceptualized as a personality trait that contributes to the development and severity of somatic and psychopathological disorders (Bach \& Bach, 1995; Parker et al., 1991). More recently, results from other studies have suggested; instead, that alexithymia may be secondary to a variety of pathological conditions such as psychiatric depression (Haviland et al., 1998; Honkalampi et al., 2001; Nerissa et al., 2016), schizophrenia (Henry et al., 2010; Kubota et al., 2011, 2012; Fogeley et al., 2014), substance use disorders (Thorber et al., 2009; Haan et al., 2014; Cruise \& Becerra, 2018), Parkinson's disease (Costa et al., 2010; Assogna et al., 2016), multiple sclerosis, (Chalah \& Ayache, 2017) and neurodegenerative diseases (Sturm \& Levenson, 2011; Ricciardi et al., 2015).

Ever since the description of alexithymia, a considerable amount of neuro-imaging studies has addressed its neural underpinnings. In alexithymia, facets of awareness, experience, and communication of emotion are impaired. An association between alexithymia and multiple regions involved in cognitive and emotion processing and emotion regulation networks has been noted, which is consistent with the complexity of this construct (Phan, Wager, Taylor, \& Liberzon, 2002). In fact, emotion perception as an early step of emotion processing appears to 
play a central role in alexithymia and involves a ventral neural system made up of the amygdala, the insula, the anterior cingulate cortex, the prefrontal cortex and the striatum, (Phillips et al., 2003; Bermond et al., 2006; Fusar-Poli et al., 2009; Van der Velde et al., 2013 ; Kugel et al., 2008). Other cerebral areas such as the motor and somatosensory cortices, the medial frontal regions, the anterior cingulated cortex and middle temporal gyrus play a central role in emotional awareness, emotion expressivity and experience (Adolphs et al., 2000; Craig, 2002; Lane et al., 1997, 1998; Kano et al., 2003; Borsci et al., 2009; Gündel et al., 2004; Paradiso et al., 2008). The ventromedial and orbitofrontal cortex participate in emotion learning through their connections with the limbic system (Kandel et al., 1991; Malloy \& Duffy, 1994), and the basal ganglia contribute to emotional experience through the dorsolateral prefrontal cortex and the orbitofrontal circuits (Alexander et al., 1990; Moriguchi et al., 2009). Thus, all these findings associate different facets of alexithymia to the abnormalities in the prefrontal cortex (Berthoz et al., 2002; Gündel et al., 2004; Kano et al., 2013; Borsci et al., 2009), and also patients with frontal damage often exhibit alexithymic behavior (Larsen et al., 2003). However, despite the crucial implication of the prefrontal cortex as neural substrates of alexithymia (Henry \& Crawford, 2004 a,b; Crawford \& Henry, 2005) and cognitive control functions (Rossi et al., 2009; Stuss, 2011; Yuan \& Raz, 2014), the specific association between alexithymia and cognitive control has received limited attention. The lack of research exploring this link reflects a major gap in the literature given the possible implication of the executive functions as the mechanism underlying alexithymia. The term "executive functions" is conceptualized as an umbrella term comprising a set of cognitive processes and behavioral competencies that are necessary to achieve a goal (Damasio, 1995; Shallice, 1988; Stuss et al., 2005; Stuss \& Benson, 1986; Diamond, 2013). It includes verbal reasoning, problem-solving, planning, sequencing, the ability to sustain attention, resistance to interference, utilization of feedback, multitasking, cognitive flexibility, the ability to deal with 
novelty, the experience of reward and punishment, regulation of one's own social behavior, and decision-making involving emotional and personal interpretation (Burgess et al., 2000; Damasio, 1995; Grafman \& Litvan, 1999; Shallice, 1988; Stuss \& Benson, 1986; Stuss et al., 1995; Stuss et al., 2005; Bechara et al., 1999; Bechara et al., 1996; Rolls, 1995). They in fact, refer to the ability to dynamically adjust behavior to a changing environment. Studies have shown that impairments in components of executive functions may have devastating effects on people's everyday life activities or the ability to develop and maintain appropriate social relations (Goel et al., 1997; Grafman et al., 1996; Green, 1996, 2000). Because executive functions involve a heterogeneous set of skills, it is important to define which functions are most associated with alexithymia. The few studies that have addressed this question in clinical populations showed diverging results with regards to such a relationship. Henry et al. (2006) showed an association between difficulty in identification emotion facet "DIF" of the Toronto alexithymia scale (TAS-20) and both semantic and alternating fluency tasks in patients with traumatic brain injury. Wood and Williams (2007) examined the prevalence of alexithymia in traumatic brain injured patients, and its relationship to injury severity and neuropsychological abilities. Their results confirm a high prevalence of alexithymia after traumatic brain injury, without noting a significant relationship between injury severity and the presence of alexithymia. A negative relationship was found between alexithymia and verbal and sequencing abilities, but there was no relationship with executive dysfunction or any other cognitive domain. Similarly, Dulau et al. (2017) evaluated the relationship between alexithymia and cognitive measures and they also showed non-association between alexithymia and attention, information processing speed, memory, and executive functions. However, Costa et al. (2007) investigated the neuropsychological correlates of alexithymia in a population of 70 non-demented Parkinson's disease patients and 70 controls. They found association between tasks requiring visuo-spatial processing and the "difficulty identifying 
feelings" facet of the Toronto Alexithymia Scale-20 (TAS-20). Also, the study of Bogdanova et al., (2010) noted significant correlation between higher levels of alexithymia and performance on neuropsychological measures of attention, executive and visuospatial functions in patients with human immunodeficiency virus (HIV).

Furthermore, studies with non-clinical samples also showed different patterns of relationship between alexithymia and executive functions. Lamberty and Holt (1995) administered tests of verbal and visuo-spatial ability and the TAS-20 to a neurologically intact sample of combat veterans. They found that TAS scores negatively correlated with measures of verbal intelligence and Stroop test, suggesting that "non-organic" alexithymia may partly be a consequence of poorly developed verbal ability. Xiong-Zhao et al., (2006) and Zhu et al. (2006) explored the cognitive function of normal subjects with different degrees of alexithymia. Results indicate a significant negative correlation between TAS-20 scores and Wisconsin Card Sorting test (WCST) performance. These results suggest that alexithymia is related to poorer executive functioning abilities. Other studies which examined the relationship between alexithymia and specific domains of cognitive function indicate that alexithymia is associated with nonverbal/visuospatial abilities (Onor \& al., 2010) while others find that it is specific to verbal abilities (Lamberty \& Holt, 1995). In the study by Koven et al. (2010), 104 normal adults completed the TAS-20, emotional intelligence and mood awareness scales as well as an ecologically-sensitive measure of discrete executive functions in daily life (BRIEF-A; Roth et al., 2005). To identify specific facets of alexithymia, a principal component analysis of all items of the TAS-20 was conducted. This yielded two specific factors: "Emotional Clarity", which measures the ability to identify and label emotions, and "Emotional Monitoring", which captures the ability to perceive and control one's emotions. The results showed that only "Emotional Clarity" predicted worse performance across 
multiple executive function domains, including behavioural initiation/inhibition, set-shifting, self-monitoring, working memory, error recognition, and ability to plan and organize. No relationship was found between "Emotion Monitoring" and patterns of cognitive performance. Zhang et al. (2011) used the Attention Network Test (ANT; Fan et al., 2002) which assess three separate attention systems -alerting, orientating, and conflict- to explore potential deficits of executive functions in normal subjects with high TAS-20 scores. The authors found that normal subjects with higher alexithymia had significantly higher conflict scores on the conflict incongruent trials. No significant differences were found in the orientating and alerting attention systems. The selective impairment in conflict processing, considered as one core function of executive control, provides further evidence of an association between alexithymia and impaired executive functioning. In more recent studies, Santorelli et al. (2015) examined the associations between TAS-20 and different verbal and visuo-spatial executive tasks in healthy young and elderly adults. Results showed a greater difficulty describing feelings associated with poorer executive verbal fluency tasks. The authors explain the association between alexithymia and verbal executive measures due to shared prefrontal circuitry involved in emotion regulation. Correro et al. (2016) used a battery of neuropsychological tests and the TAS-20 to examine executive functions and alexithymia in a sample of young and elderly adults. They found that the executive function/processing speed component represented by the Trail-making Test, Symbol-Digit Modalities Test, and Category Fluency task showed significant prediction of the TAS-20 facet of difficulty describing feelings.

Given the findings of these studies, it remains unclear which specific aspects of executive functions are implicated in alexithymia. There are few studies is very small and the executive tasks used in most of them are limited. To our knowledge, no study to date has examined the 
relationship between facets of alexithymia and a large battery of executive functioning. To address this gap, this study uses a broadband measure of executive tasks to better understand the relationship between executive functions and alexithymia in patients with different degrees of prefrontal cortex damage compared to both control groups formed from patients with parietal lesions and normal control participants. The parietal control group allows us to specify whether higher levels of alexithymia are specific consequence of prefrontal lesions or results from simply having a general brain damage. The question of a lesion laterality impact on alexithymia is also addressed.

Furthermore, we investigated the relationship between alexithymia and a large set of executive functions tasks assessing inhibition, flexibility and planning. We expected that patients with prefrontal cortex damage would be dysexecutive regarding their impaired performance on inhibition, flexibility and planning tasks, and would show a significantly higher level of alexithymia compared to both parietal patients and control participants. Moreover, we hypothesized that different components of the alexithymia construct would be consistently but differentially related to the three executive processes of inhibition, flexibility and planning. For instance, the capacity for "identifying feelings" requires the ability to discriminate feelings and to update them in correspondence to the variations in the context. This could not be effective without the involvement of the both inhibition and flexibility processes. In fact, these processes sustain the cognitive and behavioral adaptive subject's ability to initiate new sequences of thought or action, to inhibit others, and to alternate between cognitive operations (Burgess \& Shallice, 1996). Similarly, the inhibition and shifting processes are important to alternate different thinking states such as internal and external thinking. Finally, the planning processes are also required for both aspects of identifying and describing emotions. They allow the subjects, through emotion processing, to 
generate a plan of actions, to organize their behavior and to set priorities in the face of two or more competing tasks in order to deal adequately with the environment demands (Shallice \& Burgess, 1991). So, we hypothesized that all facets of alexithymia construct would be associated, as already argued, with different aspects of executive control.

\section{Method}

\subsection{Participants}

\subsubsection{Frontal patients}

Twenty patients with circumscribed prefrontal cortex lesions [16 men and four women] recruited from the department of neurosurgery participated in this study after giving their informed consent in accordance with the declaration of Helsinki. They showed an overall mean age of $\mathrm{M}=40.95, \mathrm{SD}=13.03$; years of education: $\mathrm{M}=7.32, \mathrm{SD}=2.22$; IQ in the Test of Nonverbal Intelligence “TONI-2”, $\mathrm{M}=95.56, \mathrm{SD}=3.81$ (see Brown, Sherbenou, \& Johnsen, 1989). The lesion etiologies of our patient group were heterogeneous including haemorrhagic contusion $(n=7)$, meningioma $(n=3)$, oligodendroglioma $(n=3)$, oligoastrocytoma $(n=2)$, astrocytoma $(n=2)$, haematoma $(n=2)$, and cavernoma $(n=1)$. The haematomas and haemorrhagic contusions were confirmed by CT scans, and different types of tumours were confirmed by magnetic resonance imaging (MRI: T1, T1injection, T2, Diffusion). Ten lesions were right-sided and 10 lesions were left-sided (see Table 1).

\section{(Insert table 1)}


All patients were right-handed and screened negative for history of psychiatric or neurological diseases. They were tested in the Department of Neurosurgery on average $[\mathrm{M}=$ 159.33, $(\mathrm{SD}=37.6)$ ] days after the surgery.

Then, using the mricro software (www. mricro.com; Rorden \& Brett, 2000) lesions were reported on slices of a T1-Weighted template MRI scan from the Montreal Neuroradiological Institute, orientated to approximately matched Talairach space (Talairach \& Tournoux, 1988). Figure $1 \mathrm{a}$ et $\mathrm{b}$ shows the lesion location of each patient and the lesion overlay of the scans of the twenty frontal patients.

\section{(Insert figure 1 and table 2)}

Lesions were then superimposed onto the Automated Anatomical Labeling (AAL) template provided by Mricro (Tzourio-Mazoyer et al., 2002). The software allows us to calculate the total lesion volume (in $\mathrm{cm}^{3}$ ) and to identify the cerebral regions affected by the lesion with reference to the list of anatomical ROIs (regions of interest) provided by TzourioMazoyer et al. (2002). The details of the lesion volume $\left(\mathrm{cm}^{3}\right)$ and the damaged anatomical structures for each patient are summarized in Table 2 .

\subsubsection{Parietal patients}

Ten right-handed patients [ 8 men and 2 women, age: $\mathrm{M}=38.17$, SD 7.52; educational level: $\mathrm{M}=8.14, \mathrm{SD}=1.56 ;$ "TONI-2" $\mathrm{M}=95.12, \mathrm{SD}=2.81]$ with focal parietal damage were also recruited from the Department of Neurosurgery. All lesion characteristics were confirmed by MRI (T1, T1injection, T2, Diffusion). 


\section{(Insert Table 3)}

Five patients showed right parietal lesions and five left parietal lesions. The lesion etiologies of all patients are shown in detail in table 3. Lesion volume for each patient and the damaged cerebral regions were identified using Mricro, and in the same way as for the frontal group (see Table 4 and Figure 2 a et b).

(Insert Figure 2 and Table 4)

The parietal patients showed a mean lesion volume of $9.56 \mathrm{~cm}^{3}$ (SD: 7.65) which is significantly different from the lesion volume of the frontal patient group [ $\left.\mathrm{t}_{(28)}=3.26, \mathrm{p}<01\right]$. They were also without history of psychiatric or neurological disease. All patients were assessed on average $\mathrm{M}=160.1(\mathrm{SD}=19.85)$ days after the surgery and they provided informed consent in accordance with the declaration of Helsinki.

\subsubsection{Control participants}

The control participants group was composed of 30 men and four women (age: $M=39.03$; $\mathrm{SD}=12.86$; years of education: $\mathrm{M}=8.15, \mathrm{SD}=2.7 ; \mathrm{IQ}$ in "TONI-2", $\mathrm{M}=95.71, \mathrm{SD}=4.17$ ) with no known neurological or psychiatric disorders. They were matched by cultural and demographic characteristics to the prefrontal patients. Thus, non-significant difference was noted between control participants and frontal patient groups on age, intelligence and years of education [all $p>0.28]$. 


\subsection{Materials}

\subsubsection{Executive functions}

A battery of neuropsychological tests was administered to assess executive functions. This battery is composed of a large set of tasks which investigate processes of inhibition, flexibility, planning, inductive reasoning and working memory. The neuropsychological tests are listed below in relation to the cognitive functions they investigate.

\section{Inhibition}

\section{Stroop Task}

The Color Stroop task (Stroop, 1935) consists in a series of colour names or squares printed on sheets of paper and grouped by condition: Naming, Reading and Incongruence. Each condition entailed one test sheet containing 100 stimuli. In the Naming condition, the stimuli were coloured rectangles. In the Reading condition, the stimuli were colour word names printed in black. In the Incongruence condition, the stimuli were colour words, written in a different ink colour (eg. red written in blue). In each condition, subjects are instructed to read the words, name the colours or name the colour names printed in an incompatible colour of ink as quickly and accurately as possible. Measures relating to speed and accuracy are assessed

\section{The Hayling Sentence Completion Task}

The Hayling task developed by Burgess and Shallice (1997), was designed to assess both initiation speed and response suppression. The two sections of the test each consist of 15 
sentences, each missing the last word. In the section "Response initiation", subjects were instructed to provide an appropriate word to complete a sentence from which the last word was missing "eg. The captain wanted to stay with the sinking SHIP". In the section "Response suppression", Subjects were required to provide a word which made no sense at all in the context of the sentence from which the last word was missing "eg. Most cats see very well at BANANA". For all trials, if a participant gave an erroneous response (related to the sentence, or the automatically activated word), the examiner repeated the instructions and told the participant that his or her response was too closely related to the sentence. No time limit was given for responding. However, most responses (whether correct or incorrect) were given within 60 seconds. Outcome measures are response latencies for the two sections and the categories of response-error scores for the "Response suppression" section.

\section{Flexibility}

\section{Verbal Fluency Tasks}

Fluency tasks require the generation of words that meet specific criteria in a short time period. Common types of fluency are semantic and phonemic. In the semantic fluency task, subjects are required to retrieve words by semantic category such as types of animal for two minutes. In the phonemic fluency task, subjects must retrieve words beginning with a specific letter "P" also for two minutes. Scores are the number of words generated in each type of verbal fluency task. 


\section{The Trail Making Test}

The Trail Making Test (TMT) was originally designed as a part of the Army Individual Test Battery (1944), and subsequently incorporated into the Halstead-Reitan Battery (Reitan \& Wolfson, 1985). The purpose of the TMT is to test speed of processing, sequence alternation, cognitive flexibility, visual search, motor performance, and executive functioning. The TMT consists of two parts (A and B) that must be performed as quickly and accurately as possible. TMT-A requires subjects to draw lines sequentially connecting in ascending order 25 encircled numbers randomly distributed on a sheet of paper (i.e., 1-2-3-4, etc.). In TMT-B, the subject must alternate between numbers (1-13) and letters (A-L) while connecting them (i.e., 1-A-2-B-3-C, etc.). The score on each part represents the amount of time required to complete the task. The difference score (B-A) is meant to remove the speed component from the test evaluation. Also, we quantify errors as an index of cognitive flexibility.

\section{The Modified Card Sorting Test}

The Modified Card Sorting Test (MCST; Nelson, 1976) is a revised version of the Wisconsin Card Sorting Test (Milner, 1963). The MCST consists of four stimulus cards, which are unique for colour, shape, and number of items, and two sets including 24 response cards each. Each response card has one attribute in common with each of the stimulus cards. The subject has to sort the cards according to a specific criterion that, however, may change during the task. After each response, the examiner indicates whether it was right or wrong. A criterion is considered complete if the subject makes six consecutive correct responses. Three separate scores are computed for the time spent on the task, number of categories completed and the number of errors classified as perseverative and non-perseverative. 


\section{Planning}

\section{The Modified Six Elements Task}

The Modified Six Elements Task (BADS; Wilson, Alderman, Burgess, Emslie, \& Evans, 1996) is a simplified version of the original six elements task (Shallice \& Burgess, 1991).

It was designed to assess abilities to plan, to organize and monitor one's own behaviour and to manage time. Participants must carry out three simple tasks (picture naming, arithmetic and dictation), each task divided into two sections (A and B) over a ten-minute period, whilst obeying a simple rule (do not carry out two of the same tasks consecutively). Whilst participants are not expected to complete each task, they must carry out at least part of all six. It is not important how well the participant performs the individual component tasks. Performance is measured as the number of tasks attempted, the number of rule breaks, and the maximum time spent on any individual subtask.

\section{The Tower of London Task}

The Tower of London Task (TOL; Owen et al., 1990) requires the movement of three different-colored balls (red, yellow and blue) across three different-sized pegs in order to duplicate the goal configuration in the designated number of moves. Participants were asked to transform the start state into the goal state in a predetermined number of moves while following three rules: (1) only one ball may be moved at a time, (2) a ball may not be placed on the table or held in the hand while another ball was being moved, and (3) three balls may be placed on the tallest peg, two balls on the middle peg, and only one ball on the shortest peg. The problems ranged in move length from three to six moves. The outcome measures are 
the latency time or preplanning time (time between seeing the beads and making the first move), the move time (time spent on executing the plan), and the number of movements.

\section{Inductive Reasoning}

\section{The Brixton Spatial Anticipation Task}

In the Brixton Spatial Anticipation task (Burgess \& Shallice, 1997), participants were presented with a 56-page stimulus booklet. Each page contained an array of 10 circles (two rows of five circles) which were each numbered from 1 to 10 . Participants are required to discover the rules underlying the placement of a filled black circle among this grid of unfilled circles. This meant that, participants were required to point to where they thought the filled circle would be on the next page based on the pattern or rule inferred from the previous pages. Responses were considered correct if they followed the present pattern, and on trials where the rule changed, a response was correct if it followed where the blue dot would have next moved if the rule had not changed. The total number of errors and rule breaks across 56 trials was used as the outcome measure.

\section{Working Memory}

\section{The Digit Span Task}

In the Digit Span task, a series of digits are presented for subjects and they are asked to repeat these numbers in the same sequence order (Forward digit span) or the reverse sequence order (Backward digit span). The digit span consists of the length of the longest list a person can remember. 


\section{The Dual Task}

The procedure for the dual-task paradigm proposed by Baddeley et al. (1986) consisted of performing a primary task concurrently with a secondary task. In the single-task condition, each participant performed the primary task alone for two minutes. In the dual-task conditions, the participant was instructed to perform both the primary and secondary tasks concurrently and as accurately as possible, also for two minutes. An index score "MU" is calculated based on comparisons between single-task performance on these two tasks, and performance on the tasks under dual-task conditions.

\subsubsection{The Toronto Alexithymia scale}

The Toronto Alexithymia Scale (TAS-20; Bagby, Taylor, \& Parker 1994) is the most widely used measure of alexithymia. It includes 20 items, rated on a scale from 1-5, yielding scores between 20 and 100, with higher scores representative of more severe alexithymic traits. The TAS-20 taps three distinct facets that correspond to the following sub-scales: "Difficulty Identifying Feelings" (DIF), "Difficulty Describing Feelings" (DDF), and "ExternallyOriented Thinking" (EOT). These facets can be considered to capture difficulties in the cognitive processing of emotions associated with alexithymia. The total score on the questionnaire allows categorizing subjects as non-alexithymic (scores ranging from 20 to 51), borderline alexithymic (scores ranging from 52 to 60 ), or alexithymic (scores $\geq 61$; Taylor et al., 1988, 1997)

\subsection{Data analysis}


Statistical analysis was conducted using Statistica 7.0 from StatSoft (Inc. 1984-2006). Application of the Kolmogorov-Smirnov normality test showed that data of the frontal patients and parietal patients are not normally distributed. Thus, between-group comparisons of frontal patients, parietal patients and control participants are made using the kruskall Wallis Anova test followed by the Mann-Whitney U-tests for pairwise comparison on executive tasks and TAS-20 alexithymia scale. The association between executive tasks and the three facets of TAS-20 were examined using Spearman Correlation analysis for the both groups. Multiple regression analysis is also used to examine whether performance on executive tasks predicted performance on the different facets of the TAS-20. The threshold of significance in multiple comparisons and regression analysis was corrected using the Bonferroni test. All analyses with $P$ value $<0.05$ indicated statistical significance.

\section{Results}

\subsection{Comparison between frontal patients, parietal patients and control participants on measures of executive functions}

Table 5 summarizes performance of frontal patients, parietal patients and control participants group on all indices of executive tasks.

(Insert table 5)

The Mann-Whitney U-test indicates that frontal patients are significantly impaired relative to the control participants in all indices of executive tasks assessing inhibition, flexibility and planning processes. The only measures in which non-significant difference was noted between the frontal patients and control participants is the forward span $[U=368 ; p=.90]$. Moreover, compared with parietal patients, the frontal patients were also significantly 
impaired on several executive measures except in the "rules breaks" of the Brixton task $[\mathrm{U}=256 ; \mathrm{p}=.76]$, the six elements task $[\mathrm{U}=264 ; \mathrm{p}=.88]$, the "number of movements" of the Tower of London Task $[\mathrm{U}=218 ; \mathrm{p}=.66]$, and the forward span $[\mathrm{U}=248 ; \mathrm{p}=.72]$. Similarly, the pair-wise comparison between parietal patients and control participants showed that the patients group is significantly impaired relative to the control participants in the "Shallice error score" of the Hayling task, the "rules breaks" of the Brixton task, the six elements task and the "number of movements" of the Tower of London Task [All $\mathrm{p}<.01]$.

Finally, a comparison of the frontal patients regarding their lesion side did not show a significant difference between right and left frontal subgroups on all executive measures [all $\mathrm{p}>$.23]. But, these two groups were significantly impaired compared to control participants on almost all executive measures except forward span [U=208; $p=.69]$.

\subsection{Comparison between frontal patients, parietal patients and control participants on the Toronto Alexithymia Scale (TAS-20)}

The TAS-20 results of frontal patients, parietal patients and control participants group are shown in Figure 3.

\section{(Insert Figure 3 and Figure 4)}

The Kruskal-Wallis test indicated a main group effect $[H=14.24 ; \mathrm{p}<.01]$ between all of these groups. Mann-Whitney post hoc tests noted significant difference between frontal patients and control participants on the total TAS-20 score $[\mathrm{U}=195 ; \mathrm{p}<.01]$ and the two facets of difficulty identifying feelings "DIF" $[\mathrm{U}=205 ; \mathrm{p}<.01]$ and externally oriented thinking "EOT" $[\mathrm{U}=$ 217.5; $\mathrm{p}<.01]$. However, the difference for the difficulty describing feelings facet "DDF" [U= 
281.5; $p=.12$ ] was not significant. Similarly, the same patterns of results were noted when we compared the frontal patients with parietal patients. The frontal patients were significantly impaired relative to parietal patients on total TAS-20 and both "DIF" and "EOT" facets [All $\mathrm{p}<.01]$ but not the "DDF" facet $[\mathrm{U}=296 ; \mathrm{p}=.16]$. However, there were no significant differences between the parietal patients and control participants on the total TAS-20 score and its three facets $[$ All $\mathrm{p}>$.34]. Then, we compared TAS-20 performance between frontal patients with different hemispheric lesion sides (see Figure 4). There were no significant differences between right and left frontal subgroups on the "DIF", "DDF", "EOT" facets and the total TAS-20 score $[$ All $\mathrm{p}>.31]$.

\subsection{Correlation between executive measures and different facets of the TAS-20}

The relationship between executive and working-memory tasks and the different facets of the TAS-20 are illustrated in Table 6 for frontal patients, parietal patients and the control participants.

\section{(Insert Table 6)}

For the control participants group, significant correlations were obtained between the "DIF" facet of TAS-20 and some indices of executives' tasks. The "DIF" was significantly and negatively correlated with "B-A" time scores of the Hayling task $[\mathrm{r}=-.44 ; \mathrm{p}<.01]$ and the number of correct words on the phonemic fluency task $[\mathrm{r}=-.48 ; \mathrm{p}<.01]$. This meant that higher scores on the "DIF" indicative of increasing difficulty in identifying emotions is associated with poorer performance on the Hayling and fluency tasks. Moreover, the "DIF" facet was also significantly but positively correlated with non-perseverative error scores of the $\operatorname{MCST}[\mathrm{r}=.48 ; \mathrm{p}<.01]$ and number of rule breaks of the six elements task $[\mathrm{r}=.47 ; \mathrm{p}<.01]$. So, the higher the alexithymia score on "DIF", the higher are the number of errors on these two tasks assessing flexibility and planning processes. Furthermore, only one positive correlation 
was noted between the "DDF" facet and number of rule breaks on the modified six elements task $[\mathrm{r}=.46 ; \mathrm{p}<.01]$. The total score on the TAS-20 scale was also positively correlated with non-perseverative error scores of the MCST $[\mathrm{r}=.42 ; \mathrm{p}<.01]$ and number of rule breaks of the six elements task $[\mathrm{r}=.45 ; \mathrm{p}<.01]$. No correlation was found between the "EOT" dimension of the TAS-20 and all executive measures.

Within the parietal patients, the "DIF" facet of the TAS-20 was significantly and positively correlated with the Shallice error scores of the Hayling task $[\mathrm{r}=.52 ; \mathrm{p}<.01]$, the non perseverative errors of the MCST [r=.50; $\mathrm{p}<.01]$, and the number of rules breaks of the modified six elements tasks $[\mathrm{r}=.52 ; \mathrm{p}<.01]$. Thus, difficulty identifying emotion is associated with a deficit in the three executive processes of inhibition, flexibility and planning. For the "EOT" facet, only one significant positive correlation was noted with non perseverative errors of the MCST [r=.52; $\mathrm{p}<.01]$. However, no correlation was noted for the "DIF" facet of the TAS-20 with all executive tasks. The total TAS-20 score is significantly and positively correlated with the same executive indices significantly associated to the "DIF" facet.

For the frontal patients group, a significant negative correlation was noted between "DIF" facet of TAS-20 and number of correct words on the phonemic fluency task $[r=-.59 ; \mathrm{p}<.01]$ whereas significant positive correlations were noted between "DIF" and perseverative error scores of the MCST $[\mathrm{r}=.48 ; \mathrm{p}<.01]$ and number of rule breaks of the modified six elements task $[\mathrm{r}=.47 ; \mathrm{p}<.01]$. These associations indicated that a higher degree of difficulty in identifying emotion is associated with impaired performance on flexibility and planning tasks. Furthermore, only one significant positive correlation was found between the "DDF" facet of TAS-20 and number of rule breaks on the modified six elements task $[\mathrm{r}=.50 ; \mathrm{p}<.01]$. The "EOT" facet of TAS-20 showed correlations with almost all indices of the MCST. The "EOT" correlated significantly and negatively with the number of categories completed $[\mathrm{r}=-.71 ; \mathrm{p}$ $<.01]$ and positively with both perseverative $[\mathrm{r}=.67 ; \mathrm{p}<.01]$ and non-perseverative errors 
[r=.54; $\mathrm{p}<.01]$ of the MCST. This TAS-20 facet also correlated significantly and positively with the Shallice error scores of the Hayling task $[\mathrm{r}=.66 ; \mathrm{p}<.01]$ and the time "B-A" scores of the Trail Making task $[\mathrm{r}=.56 ; \mathrm{p}<.01]$. Finally, the total score of TAS-20 correlated significantly and negatively with the number of correct words on the phonemic fluency task $[\mathrm{r}=-.49 ; \mathrm{p}<.01]$ and number of categories completed on the MCST $[\mathrm{r}=-.52 ; \mathrm{p}<.01]$ but positively with both perseverative $[\mathrm{r}=.50 ; \mathrm{p}<.01]$ and non-perseverative errors $[\mathrm{r}=.48 ; \mathrm{p}<.01]$ of the MCST, the time "B-A" scores $[\mathrm{r}=.49 ; \mathrm{p}<.01]$ of the Trail Making Task, the Shallice error scores of the Hayling task $[r=.50 ; p<.01]$ and number of rule breaks $[r=.50 ; p<.01]$ on the modified six elements task. These patterns of association suggested that increasing alexithymia is associated with impaired executive functions.

\subsection{Regression analysis}

To determine whether significant correlates were uniquely predictive of difficulty identifying feelings "DIF", describing feelings "DDF", externally oriented thinking "EOT" and total level of alexithymia, multiple regressions were conducted. All executive indices that are been significantly correlated to different facets of the TAS-20 scale were entered as predictors in the regression analysis. The scores on "DIF", "DDF", "EOT" facets and Total-TAS- 20 are entered as dependent measures. The results showed that for control participants, greater "DIF" was predicted by greater number of non-perseverative errors on the MCST $\left[R^{2}=.25 ; F=\right.$ $8.76 ; p=.001]$, rule breaks on the modified six elements task $\left[R^{2}=.28 ; F=9.36 ; p=.001\right]$ and poorer phonemic fluency performance $\left[R^{2}=.23 ; F=8.54 ; p=.001\right]$. The "DDF" was predicted by the rule breaks of the six elements tasks $\left[R^{2}=.22 ; F=8.32 ; p=.01\right]$ and the Total TAS-20 score was predicted by both the number of errors on the MCST $\left[R^{2}=.28 ; F=\right.$ 
9.24; $p=.001]$ and rule breaks on the modified six elements task $\left[R^{2}=.29 ; F=9.56 ; p=\right.$ $.001]$.

Within the parietal patients group, both of "DIF" facet and total TAS-20 score were predicted by non-perseverative errors of the MCST $\left[R^{2}=.24 ; F=8.12 ; p=.001\right]$, rules breaks of the modified six elements task $\left[R^{2}=.25 ; F=8.92 ; p=.001\right]$ and Shallice error scores of the Hayling task $\left[R^{2}=.23 ; F=7.88 ; p=.001\right]$. The "EOT" facet is predicted only by the rules breaks of the modified six elements task $\left[R^{2}=.24 ; F=8.46 ; p=.001\right]$.

For the frontal patients group, the "DIF" facet was predicted by perseverative errors on the $\operatorname{MCST}\left[R^{2}=.35 ; F=9.89 ; p=.001\right]$, rules breaks on the modified six elements task $\left[R^{2}=.34\right.$; $F=9.88 ; p=.001]$ and poorer performance on the phonemic fluency task $\left[R^{2}=.23 ; F=7.89\right.$; $p=.001]$. However, only the rule breaks indices of the six elements task predicted difficulties in describing feelings "DDF" $\left[R^{2}=.24 ; F=8.48 ; p=.001\right]$. The "EOT" facet was predicted by several indices of executive tasks. Regressions were significant for the perseverative errors $\left[R^{2}=.30 ; F=10.08 ; p=.001\right]$, non-perseverative errors $\left[R^{2}=.20 ; F=7.68 ; p=.001\right]$, and the number of categories completed $\left[R^{2}=.32 ; F=10.12 ; p=.001\right]$ on the MCST, the time "B-A" of the Trail Making Task $\left[R^{2}=.20 ; F=7.64 ; p=.001\right]$ and Shallice error scores on the Hayling task $\left[R^{2}=.28 ; F=10.08 ; p=.001\right]$. Regarding overall level of alexithymia, analyses revealed that higher alexithymia was also predicted by the perseverative errors $\left[R^{2}=\right.$ $.20 ; F=7.68 ; p=.001]$, non-perseverative errors $\left[R^{2}=.20 ; F=7.64 ; p=.001\right]$, and the number of categories completed $\left[R^{2}=.21 ; F=7.83 ; p=.001\right]$ on the MCST, poorer phonemic fluency $\left[\mathrm{R}^{2}=.20 ; \mathrm{F}=7.66 ; p=.001\right]$, the time "B-A" of the Trail Making Task $\left[R^{2}\right.$ $=.20 ; F=7.64 ; p=.001]$, the Shallice error scores on the Hayling task $\left[R^{2}=.20 ; F=7.64 ; p\right.$ $=.001]$ and rules breaks on the modified six elements task $\left[R^{2}=.20 ; F=7.65 ; p=.001\right]$. 
Thus, all of these results suggested that higher alexithymia is predicted by poorer executive performance.

\subsection{Lesion analysis and lesion volume}

The frontal patients group showed an average lesion volume of $\left[\mathrm{M}=22.32 \mathrm{~cm}^{3}\right.$; $\left.\mathrm{SD}=19.46\right]$ and the parietal patients group a mean lesion volume of [9.56 $\mathrm{cm}^{3}$; SD: 7.65]. Using regression analysis, we examined the possible association between different facets of the TAS-20 and the lesion volume of patients. For the parietal patients, no significant association was noted between lesion volume and different facets of the TAS-20 $\left[\mathrm{R}^{2}=.10 ; \mathrm{F}=1.05 ; \mathrm{p}=\right.$ .33]. However, for the frontal patients group, a significant correlation was found between lesion volume and "DIF" [R $\left.\mathrm{R}^{2}=.22 ; \mathrm{F}=5.84 ; \mathrm{p}<0.01\right]$, "EOT" $\left[\mathrm{R}^{2}=.23 ; \mathrm{F}=6.08 ; \mathrm{p}<.01\right]$ and total scores on TAS-20 $\left[\mathrm{R}^{2}=.20 ; \mathrm{F}=5.78 ; \mathrm{p}<.01\right]$. However, non-significant association was noted between the lesion volume of our frontal patients and their scores on the "DDF" $\left[\mathrm{R}^{2}=\right.$ $0.10 ; \mathrm{F}=1.06 ; \mathrm{p}=.32]$.

Moreover, using overlap lesion images and lesion subtraction analysis provided by Mricro, we examined the anatomical lesions underlying alexithymia. As a first step, frontal patients were classified into two groups based on their overall score on the TAS-20. The nonalexithymic group consisted of ten patients with total "TAS-20 scores < "61" [6 patients considered non-alexithymic with scores ranging between "20 to 51" and 4 patients borderline alexithymic with scores ranging between "52 and 60"] and the alexithymic group also formed from ten patients with total "TAS-20 scores $\geq 61 "$ ". Using mricro, the lesions from each patient were overlaid to identify the common cerebral regions damaged in each group (see Figure 5 a, b et $c)$. 


\section{(Insert Figure 5. a, b, c)}

Then, regions relevant for the alexithymia were identified by means of lesion-subtraction analysis (Fig.3.c). As these subtractions were made between groups of different sizes, relative percentages were used rather than absolute values. The red color indicates the common damaged brain regions involved in the decision-making deficit (41-60\%). The blue color represents the damaged brain regions $(1-40 \%)$ that were not involved in the decision-making deficit. Our results indicate that alexithymia was predominantly associated with a large prefrontal network including the right superior frontal gyrus (SFG), the right and left medial superior-frontal gyrus (MedSFG), the right middle-frontal gyrus (MFG), the right and left anterior cingulate gyrus (ACING), the right and left orbital part of the superior-frontal gyrus (OrbSFG), the right medial-orbital-frontal gyrus (OrbMFG) and the right and left orbital part of the inferior-frontal gyrus (OrbIFG).

\section{Discussion}

The aim of this work was to study the impact of the focal prefrontal cortex damage on alexithymia and its relationship with executive functions. Therefore, in accordance with our predictions, frontal patients were dysexecutive and showed increased levels of alexithymia. This effect was primarily driven, in our frontal group, by the significant difference on the executive measures and TAS-20 subscales of "DIF" and "EOT" compared to both parietal patients and control participants. In fact, impaired executive performances indicate that frontal patients have lost the efficiency of their cognitive control ability. Moreover, the impaired "DIF" facet of TAS-20 reveals the inability of frontal patients to accurately identify, symbolize and interpret their internal affective states, to experience continuous problems in 
processing their emotions at a cognitive level and regulating them. Whereas, an impaired "EOT" facet indicates that patients are less introspective as they engage in more external events over internal states relative to control participants. This could be understood to be a deficit in emotional or cognitive aspects which tap into different components of alexithymia from those measured by the "DIF" and "DDF" sub-scales. Therefore, "DIF" and "DDF" seem relatively closely related as both explicitly refer to emotions, whereas "EOT" specifically assesses a style of thinking which refers to the cognitive mode not necessarily including the experience of an emotion. However, the non-significant difference noted between frontal patients and both control groups on the "DDF" suggest at the very least the intriguing assertion that perceiving and expressing one's emotion are distinct processes. Beyond that, our results confirmed that the presence of frontal abnormalities impacts upon the control functions implicated in the regulation of cognitive and affect processes, which underlie different aspects of alexithymia (Taylor et al., 1997; Donges \& Suslow, 2017). The present evidence for acquired alexithymia following circumscribed prefrontal damage is in agreement and also extends the previous data of brain lesion studies which suggested that alexithymia can be acquired following traumatic brain injury (Henry et al., 2006; Williams \& Wood, 2001, 2010) or neurodegenerative disease (Sturm \& Levenson, 2011; Assogna et al., 2016) as well as the neuro-imaging findings showing a particular vulnerability of frontal cortical regions for alexithymia (Berthoz et al., 2002; Kano et al., 2003; Gündel et al., 2004; Wingbermuhle et al., 2012; Van der Velde et al., 2013; Xua et al., 2018). In fact, our results have shown that higher scores on "DIF" and "EOT" facets and the overall TAS-20 score correlate with the lesion volume of the frontal patients group. Moreover, lesion analysis had linked alexithymia with damage of the medial and orbital prefrontal gyrus and the anterior cingulate gyrus. These regions have also been identified in past studies to be related to various features of alexithymia such as emotion processing (Donges \& Suslow, 2017), conscious 
awareness of emotion and self (Lane et al., 1998; Bird \& Viding, 2014), interoceptive awareness, (Van der Velde et al., 2014; Brewer et al., 2016; Murphy et al., 2017, 2018), experiencing a negative affect (Suslow \& Donges, 2017) and processing reward (Goerlich et al., 2017), and they are also a part of a larger network involving temporal areas, the amygdala (Leweke et al., 2004; Kugel et al., 2008; Reker et al., 2010; Pouga et al., 2010), and the insula (Bird et al., 2010; Hogeveen et al., 2016; Xua et al., 2018). In summary, our findings provide causal support for the view that the prefrontal cortex regions are one of the key correlates of alexithymia.

In response to the second important issue of this work, interesting patterns of association between greater levels of alexithymia and different aspects of executive control were found within frontal patients, parietal patients, and control participants. More specifically, the two facets of difficulty in identifying feelings "DIF" and externally oriented thinking "EOT" were associated with a broad range of indices of the Hayling task, the six elements task, the MCST, the phonemic verbal task and the trail making test. While only one association was found between the facet of difficulty in describing feelings "DDF" and the six elements task. With control participants, the highest association was also noted between "DIF" and indices of rules breaks on the six elements task, correct words on the phonemic fluency task, and error scores on the MCST. The "DDF" was associated with only the rules breaks of the six elements task, whereas non-association was found between "EOT" and executive tasks. However, with parietal patients, the associations found were between "DIF" and indices of rules breaks on the six elements task, Shallice error scores on the Hayling task and non perseverative errors of the MCST. The "EOT" facet was associated only with the non perseverative errors of the MCST while non-association was noted between "DDF" and all executive tasks. 
These patterns of results indicate that higher alexithymia levels on the three facets of TAS20 were consistently but differentially associated with impairment in a set of executive control tasks that could be grouped into verbal tasks (eg, the Hayling task, the phonemic fluency task), and visuo-spatial tasks (eg: MCST, the six elements task, TMT). Along the same line, past studies by Lamberty and Holt (1995), Henry et al. (2006), Wood and Williams (2007) and Santorelli et al. (2015) have provided preliminary evidence suggesting a relationship between alexithymia and verbal executive dysfunction or general verbal deficit. They considered executive verbal deficit to maybe underlie the "no words for feelings" concept of alexithymia and so could be considered as an indicator of left hemisphere dysfunction. Whereas, other studies by Costa et al. (2007), Bogdanova et al. (2013), Onor et al. (2010) suggested a specific association between alexithymia and visual spatial dysfunction. Visual spatial deficit was considered as an indicator of right hemisphere dysfunction. This relationship between alexithymia and right hemisphere functioning could reflect a more basic association between the right hemisphere and emotional processing. In fact, a right hemisphere advantage in the processing of visual-spatial information (Hamsher et al., 1992; Haxby et al., 1993; Nichelli, 1996; Warrington \& Rabin, 1970) and elaboration of emotional stimuli has been largely demonstrated in both normal subjects and neurological patients (Borod et al., 1996; Hornak et al., 1996; Caltagirone et al., 1989; Jacobs et al., 1995; Mandal et al., 1999; Troisi et al., 2002). However, based on our findings, alexithymia was associated with both executive verbal and visuo-spatial tasks and both patients with right or left prefrontal damage showed similar impaired alexithymic levels which suggested that verbal and visuo-spatial process could be both a basic mechanism underlying alexithymia. These findings provide further evidence of an interhemispheric transfer deficit in alexithymia and suggest that an alexithymic cognitive style reflects poor integration of the information 
processing of the two cerebral hemispheres (Parker et al., 1999), due to the more basic deficit of cognitive executive control mechanisms underlying emotion processing.

In fact, feeling identification requires the ability to internally discriminate feelings, to symbolize them in the verbal domain and to continuously update these feelings in correspondence to the novelty in the context which suggests the inhibition of feelings that become irrelevant for the situation. This could not be achieved without the effective involvement of the inhibition and shifting process. Moreover, the planning processes are also important but for both aspects of identifying and describing emotions. They allow the subject, during emotion processing, to deal objectively with "him- or her-self" in relation to the environment, to figure out the abstract rules, to think of alternatives, to weigh and make choices (Walsh, 1978). Planning processes also allow him or her to reflect on their emotions and to engage a strategic research in semantic or episodic memory to compare the current event with similar past emotion events, before they can pinpoint the affective state and verbalize it in respect to the actual context. This possibility is consistent with the broader literature on the interactions between neurocognition, metacognition and theory of mind (Lysaker et al., 2007, 2011; Fett et al., 2011; Pickup, 2008), and related findings suggesting alexithymia entails a deficit in thinking about one's internal states (Dimaggio et al., 2009). Finally, an optimal level of externally oriented thinking requires efficient inhibition and shifting processes. This enables the subject to alternate between different thinking states such as internal and external thinking, and so to ovoid the disbalance of these mechanisms. However, across specific clinical groups, the distribution of low- and high-scorers on the "EOT" and also on other factors of alexithymia should be different due to different central mechanisms of disorder development in these clinical groups (Mattila et al., 2006). For instance, the "EOT" should not be much present in depressed patients with perseverative 
rumination as a main central mechanism of the disorder development (Davydov et al., 2013; Papageorgiou \& Wells, 2004; Robinson \& Alloy, 2003). However, it should be more frequently found in subjects with a "psychopathic personality", who may utilize this mechanism to detach their mind/behavior from external events and to demonstrate shallow emotions in high arousal surroundings (Lander, Lutz-Zois, Rye, \& Goodnight, 2012). To sum up, emotion processing requires an adequately cognitive evaluation of the environment and a person-environment interaction in relation with the context (Moors et al., 2013), mediated by the executive control processes.

This refers to another potential explanation that comes from the concept of cognitive "appraisal" in emotion episode processing. Cognitive appraisal is recognized as an adaptive mechanism that allows a subject to weigh up the different aspects of a situation and to provide the response that is most appropriate to the context in an environment that fluctuates continuously (Scherer, 1984; Scherer, 2001; Mehu \& Scherer, 2015). Such flexible appraisal patterns differ from situation to situation and imply that the subject has a number of response patterns available and that these responses turned out to be effective in the past. However, non-flexible or rigid appraisal patterns do not allow identification of subtle important differences between situations, resulting in similar evaluation outcomes for different events which decrease the potential for adaptation (Kuppens, 2010, 2013). Often, in a socially ambiguous life, the person is required to make emotional sense from how they appraise a situation based on the available external and internal information (Barrett, Mesquita, Ochsner, \& Gross, 2007). Therefore, experienced feelings directly reflect the experienced pattern of appraised meaning, and the associated core affect, motivational and autonomous changes it implies. Thus, we suggest that frontal patients with acquired alexithymia showed deficit on the appraisal patterns that allow identifying, differentiating and communicating their emotion 
states. The appraisal theories have assigned a central role to this process in triggering and differentiating emotional episodes and in determination of the intensity and quality of feelings through synchronic changes in other components such as physiological and behavioral responses (Clore \& Ortony, 2000; Frijda, 2007; Lazarus, 1991; Roseman \& Smith, 2001; Scherer, 2001; Moors, 2013). They also specified the most important appraisal criteria that allowed differentiating emotions, such as goal relevance and goal congruence for concerns, certainty, agency and coping potential or control. Some other authors also propose criteria of novelty, expectancy, urgency, intentionality, legitimacy, fairness, and norm compatibility, which contribute to differences in emotions (for review see, Donges \& Suslow, 20017). It follows based on the appraisal criteria and mechanisms described above, that the "cognitive appraisal process" taps several aspects that are specific for executive control. Therefore, its role appears to be somewhat similar to that assigned to the Supervisory Attentionnel System (SAS; Norman \& Shallice, 1986). The SAS is responsible for regulating non-routine and novel tasks, in particular, where routine, automatic activation of behavior would not be sufficient for optimal performance (Norman \& Shallice, 1986). These include situations that involve planning or decision-making, error correction, responses that are not well-learned or contain novel sequences of actions or when anticipation of danger is required. However, even if authors suggest that the "appraisal process" is unconscious by default, Scherer (2009) has already noted that part of it can become conscious and hence become part and one determinant of the content of feelings (Scherer, 2009). Thus, the appraisal process cannot operate only at the automatic level. Therefore, we suggest that increased neuropsychological attention should be directed to the relation between a neuro-cognitive model of executive functions (SAS; Norman \& Shallice, 1986; Shallice \& Burgess, 1988) and the cognitive appraisal theory in understanding cognitive processing of emotion. In summary, all previous arguments suggest that alexithymia, like several other affective disorders, could result from 
impairment of different cognitive mechanisms, such as a deficit of inhibition, set-shifting and planning aspects of executive control or also the appraisal bias in cognitive evaluation of emotions. These cognitive mechanisms play a central role not only in the regulation of emotional processes but also in the generation of affective states that fail to be regulated (Taylor et al., 1997).

Finally, some methodological issues should be considered in the present work. First, our patients group and matched control participants are mainly men. Hence, we do not know whether, for women, the same patterns of association between alexithymia factors and executive processes would be noted. Women have been reported to be more susceptible to negative emotions than men (Yuan et al., 2009), and studies have revealed gender differences in brain structure and function (Domes et al., 2010: Kong et al., 2014). Another finding deserving comment concerns the fact that the use of self-reported instrument, which inherently lacks objectivity, may be led to underestimation of the presence of alexithymic traits. The TAS-20 has been commonly used without controlling for biases that may arise due to self-report, perhaps because the measure was reportedly designed to limit such influences (Bagby et al., 1994). However, explicit self-report measures require the alexithymic individual to be aware of and able to report on their own reduced ability to identify and describe feelings (Adenzato \& Poletti, 2013; Parling et al., 2010; Günther et al., 2016). Thus, it is to be recommended that future studies use multi-method measures such as performancebased measures for assessing of alexithymia in addition to self-report tests. Finally, little is known about the direction of causality between executive functions and alexithymia and therefore, future research is required to address this issue. Namely, which deficit occurs first a general deficit in executive functions that impairs the ability to regulate emotions, or an 
inability to identify, describe, and understand emotional feelings that causes high baseline arousal, which then impairs executive functions. 


\section{References}

Adenzato, M., \& Poletti, M. (2013). Theory of Mind abilities in neurodegenerative diseases: an update and a call to introduce mentalizing tasks in standard neuropsychological assessments. Clinical Neuropsychiatry, 10, 226 - 234.

Adolphs, R., Damasio, H., Tranel, D., Cooper, G., \& Damasio, A. R. (2000). A role for somatosensory cortices in the visual recognition of emotion as revealed by threedimensional lesion mapping. Journal of Neuroscience, 20, 2683 - 2690.

AITB (1944). Army individual test battery. In Manual of directions and scoring. Washington, DC: War Department, Adjutant General's Office.

Alexander, G. E., Crutcher, M. D., \& DeLong, M. R. (1990). Basal ganglia-thalamocortical circuits: parallel substrates for motor, oculomotor, "prefrontal" and "limbic" functions. Progress in Brain Research, 85, 119-147.

Assogna, F., Cravello, L., Orfei, M. D., Cellupica, N., Caltagirone, C., \& Spalleta, G. (2016). Alexithymia in Parkinson's disease: A systematic review of the literature. Parkinsonism and Related Disorders, 28, 1-11.

Bach, M., \& Bach, D. (1995). Predictive value of alexithymia: a prospective study in somatizing patients. Psychotherapy and Psychosomatics, 64, 43 - 48. 
Baddeley, A. D., Logie, R. H., Bressi, S., Della Sala, S., \& Spinnler, H. (1986). Dementia and working memory. Quarterly Journal of Experimental Psychology, 38A, 603-618.

Bagby, R. M., Parker, J. D. A., \& Taylor, G. J. (1994). The twenty-item Toronto Alexithymia Scale: I. Item selection and cross-validation of the factor structure. Journal of Psychosomatic Research, 38, 23-32.

Barrett, L. F., Mesquita, B., Ochsner, K. N., \& Gross, J. J. (2007). The experience of emotion. Annual Review of Psychology, 58, 373-403.

Bechara, D., Damasio, H., Damasio, A. R., \& Lee, G. P. (1999). Different contributions of the human amygdale and ventromedial prefrontal cortex to decision-making. Journal of Neuroscience, 19, 5473 - 5481.

Bechara, D., Tranel, D., Damasio, H., \& Damasio, A. R. (1996). Failure to respond automatically to anticipated future outcomes following damage to prefrontal cortex. Cerebral Cortex, 6, 215-225.

Bermond, B., Vorst, H. C. M., \& Moormann, P. (2006). Cognitive neuropsychology of alexithymia: implications for personality typology. Cognitive Neuropsychiatry, 11(3), $332-360$.

Berthoz, S., Artiges, E., Van de Moortele, P. F., Poline, J. B., Rouquette, S., Consoli, S. M., \& Martinot, J. L. (2002). Effect of impaired recognition and expression of emotions on 
frontocingulate cortices: An fMRI study of men with alexithymia. American Journal of Psychiatry, 159 (6), 961- 967.

Bird, G., \& Viding, E. (2014). The self to other model of empathy: providing a new framework for understanding empathy impairments in psychopathy, autism, and alexithymia. Neuroscience and Biobehavioral Reviews, 47, 520 - 532.

Bird, G., Silani, G., Brindley, R., White, S., Frith, U., \& Singer, T. (2010). Empathic brain responses in insula are modulated by levels of alexithymia but not autism Geoffrey. Brain, 133, 1515-1525.

Bogdanova, Y., \& Cronin-Golomb, A. (2013). Alexithymia and apathy in Parkinson's disease: neurocognitive correlates, Behavioural Neurology, 27 (4), 535-545.

Bogdanova, Y., Díaz-Santos, M., \& Cronin-Golomb, A. (2010). Neurocognitive correlates of alexithymia in asymptomatic individuals with HIV. Neuropsychologia, 48 (5), 1295 1304.

Borod, J. C., Rorie, K. D., Haywood, C. S., Andelman, F., Obler, L. K.,Welkowitz, J., Bloom, R. L., \&Tweedy, J. R. (1996). Hemispheric specialization for discourse reports of emotional experiences: Relationship to demographic, neurological, and perceptual variables. Neuropsychologia, 34, 351-359.

Borsci G, Boccardi M, Rossi R, Rossi, G., Perez, J., Bonetti, M., Frisoni, J. B. (2009). Alexithymia in healthy women: a brain morphology study. Journal of Affective Disorders, 114 (1-3), 208 - 215. 
Brewer, R., Cook, R., \& Bird, G. (2016). Alexithymia: A general deficit of interoception. Royal Society Open Science, 3(10), 150664

Burgess, P. W., \& Shallice, T. (1996). Response suppression, initiation and strategy use following frontal lobe lesions. Neuropsychologia, 34, 263-273.

Burgess, P. W., \& Shallice, T. (1997). The Hayling and Brixton Tests. Thurston, Suffolk: Thames Valley Test Company.

Burgess, P. W., Veitch, E., de lacy Costello, A., \& Shallice, T. (2000). The cognitive and neuroanatomical correlates of multi-tasking. Neuropsychologia, 38, 848-863.

Caltagirone, C., Zoccolotti, P., Originale, G., Daniele, A., \& Mammuccari, A. (1989). Autonomic reactivity and facial expression of emotions in brain damaged patients. In G. Gainotti \& C. Caltagirone (Eds.), Emotion and the Dual Brain (pp. 204 - 221). New York: Springer Verlag.

Chalah, M., Ayache, S. S. (2017). Alexithymia in multiple sclerosis: A systematic review of literature. Neuropsychologia, 104, 31- 47.

Clore, G. L., \& Ortony, A. (2000). Cognition in emotion: Always, sometimes, or never? In R. D. Lane \& L. Nadel (Eds.), Cognitive neuroscience of emotion (pp. 24-61). New York: Oxford University Press. 
Correro II, A. N., Marra, D. E., Reiter, K., et al. (2016). Executive functioning and verbal memory are predictive of alexithymia across the lifespan. Clinical Neuropsychologist, 30,425 .

Costa, A., Peppe, A., Carlesimo, G. A., Salamone, G., \& Caltagirone, C. (2010). Prevalence and Characteristics of Alexithymia in Parkinson's Disease. Psychosomatics, 51, 1, 2228.

Costa, A., Peppe, A., Carlesimo, G. A., Salamone, G., \& Caltagirone, C. (2007). Neuropsychological correlates of alexithymia in Parkinson's disease, Journal of the international Neuropsychological Society, 13 (6), 980-992.

Craig, A. D. (2002). How do you feel? Interoception: The sense of the physiological condition of the body. Nature Reviews Neuroscience, 3, 655 - 666.

Crawford, J. R., \& Henry, J. D. (2005). Assessment of executive deficits. In P. W. Halligan \& N. Wade (Eds.), The effectiveness of rehabilitation for cognitive deficits (pp. 233-246). London: Oxford University Press.

Cruise, K. E., \& Becerra, R. (2018). Alexithymia and problematic alcohol use: A critical update. Addictive Behaviors, 77, 232-246.

Damasio, A. R. (1995). Toward a neurobiology of emotion and feeling: Operational concepts and hypotheses. The Neuroscientist, 1(1), 19-25. 
Davydov, D. M., Luminet, O., \& Zech, E. (2013). An externally oriented style of thinking as a moderator of responses to affective films in women. International Journal of Psychophisiology, 87 (2), 152-164.

Diamond, A. (2013). Executive functions. Annual Review of Psychology, 64, 135-168.

Dimaggio, G., Vanheule, S., Lysaker, P.H., Carcione, A., \& Nicolò, G. (2009). Impaired selfreflection in psychiatric disorders among adults: a proposal for the existence of a network of semi independent functions. Consciousness and Cognition, 18, 653 - 664.

Domes, G., Schulze, L., Bottger, M., Grossmann, A., Hauenstein, K., Wirtz, P. H., Heinrichs, M., \& Herpertz, S. C. (2010). The neural correlates of sex differences in emotional reactivity and emotion regulation. Human Brain Mapping, 31, 758 - 769.

Donges, U. S., \& Suslow, T. (2017). Alexithymia and automatic processing of emotional stimuli: a systematic review. Reviews in the Neuroscience, 28 (3), 247-264.

Dulau, C., Deloire, M., Diaz, H., Saubusse, A., Charre-Morin, J., Prouteau, A., Brochet, B. (2017). Social cognition according to cognitive impairment in different clinical phenotypes of multiple sclerosis. Journal of Neurology, 264 (4), 740-748.

Fan, J., Mccandliss, B. D., Sommer, T., Raz, A., \& Posner, M. I. (2002). Testing the efficiency and independence of attentional networks. Journal of Cognitive Neuroscience, 14 (3), 340 - 347. 
Fett, A. K. J., Viechtbauer, W., Dominguez, M. G., Penn, D. L., Van Os, J., \& Krabbendam, L. (2011). The relationship between neurocognition and social cognition with functional outcomes in schizophrenia: A meta-analysis. Neuroscience and Biobehavioral Reviews, $35(3), 573-588$.

Fogley, R., Warman, D., \& Lysaker, P. H. (2014). Alexithymia in schizophrenia: Associations with neurocognition and emotional distress. Psychiatry Research, 218, 1-6.

Frijda, N. H. (2007). The laws of emotion. Mahwah, NJ: Erlbaum.

Fusar-Poli, P., Placentino, A., Carletti, F., Landi, P., Allen, P., Surguladze, S., Benedetti, F., Abbamonte, M., Gasparotti, R., Barale, F., Perez, J., McGuire, P., \& Politi, P. (2009) Functional atlas of emotional faces processing: a voxel-based meta-analysis of 105 functional magnetic resonance imaging studies. Journal of Psychiatry and Neuroscience, 34, 418-432.

Goel, V., Grafman, J., Tajik, J., Gana, S., \& Danto, D. (1997). A study of the performance of patients with frontal lobe lesions in a financial planning task. Brain, 120, 1805-1822.

Goerlich, K. S., Votinov, M., Lammertz, S. E., Winkler, L., Spreckelmeyer, K. N., Habel, U., Gründer, G., \& Gossen, A. (2017). Effects of alexithymia and empathy on the neural processing of social and monetary rewards. Brain Structure and Function, 222, 22352250.

Grafman, J., \& Litvan, I. (1999). Importance of deficits in executive functions. The Lancet, 354, 1921-1923. 
Grafman, J., Schwab, K.,Warden, D., Pridgen, A., Grown, H. R., \& Salazar, A. M. (1996). Frontal lobe injuries, violence, and aggression: A report of the Vietnam Head Injury Study. Neurology, 46, 1231-1238.

Green, M. F. (1996). What are the functional consequences of neurocognitive deficits in schizophrenia? American Journal of Psychiatry, 153(3), 321- 330.

Green, M. F., Kern, R. S., Braff, D. L., \& Mintz, J. (2000). Neurocognitive deficits and functional outcome in schizophrenia: Are we measuring the "right stuff"? Schizophrenia Bulletin, 26 (1), 119 - 136.

Gündel, H., López-Sala, A., Andres, O., Ceballos-Baumann, M. D., Deus, J., Cardoner, N., Marten-Mittag, B., Soriano-Mars, C., \& Pujol, J. (2004). Alexithymia correlates with the size of the right anterior cingulate. Psychosomatic Medicine, 66 (1), 132 - 140.

Günther, V., Rufer, M., Kersting, A., \& Suslow, T. (2016). Predicting symptoms in major depression after inpatient treatment the role of alexithymia. Nordic Journal of Psychiatry, 70 (5), 392-398.

Haan, H. A., Van der Palen, J., Wijdeveld, T. G. M., \& Buitelaar, J. K. (2014). Alexithymia in patients with substance use disorders: State or trait? Psychiatry Research, 216, 137-145.

Hamsher, K.D., Capruso, D.X., \& Benton, A. (1992). Visuospatial judgment and right hemisphere disease. Cortex, 28, 493- 495. 
Haviland, M. G., Shaw D. G., Cummings M. A., McMurray, J. P. (1998). Alexithymia: subscales and relationship to depression. Psychotheraoy Psychosomatics, 50 (3), 164173.

Haxby, J. V., Grady, C.L., Hoewitz, B., Salerno, J., Ungerleider, L. G., Minshkin, M., \& Shapiro, M. B. (1993). Dissociation of object and spatial visual processing pathways in human extrastriate cortex. In B. Gulyás, D. Ottoson, \& P.E. Roland (Eds.), Functional Organization of Human Visual Cortex (pp. 329 - 340). Oxford: Pergamon Press.

Henry, J. D., \& Crawford, J. R. (2004a). A meta-analytic review of verbal fluency performance following focal cortical lesions. Neuropsychology, 18, 284-295.

Henry, J. D., \& Crawford, J. R. (2004b). A meta-analytic review of verbal fluency performance in traumatic brain injured patients. Neuropsychology, 18, 621-628.

Henry, J. D., Bailey, P. E., Van Hippel, C., Rendell, P. G. \& Lane, A. Alexithymia in schizophrenia (2010). Journal of Clinical and Experimental Neuropsychology, 32 (8), $890-897$.

Henry, J. D., Phillips, L. H., Crawford, J. R., Theodorou, G., \& Summers, F. (2006). Cognitive and psychosocial correlates of alexithymia following traumatic brain injury. Neuropsychologia, 44, 62-72. 
Hogeveen, J., Bird, G., Chau, A., Krueger, F., \& Grafman, J. (2016). Acquired alexithymia following damage to the anterior insula. Neuropsychologia, 82, 142-148.

Honkalampi, K., Hintikka, J., Laukkanen, E., Lehtonen, J., \& Viinamaki, H. (2001). Alexithymia and depression: a prospective study of patients with major depressive disorder. Psychosomatics, 42 (3), 229 - 234.

Hornak, J., Rolls, E. T., \& Wade, D. (1996). Face and voice expression identification in patients with emotional and behavioural changes following ventral frontal lobe damage. Neuropsychologia, 34, 247-261.

Jacobs, D.H., Shuren, J., Bowers, D., \& Heilman, K.M. (1995). Emotional facial imagery, perception, and expression in Parkinson's disease. Neurology, 45, 1696-1702.

Kandel, E. J., Schwartz, J. H. , \& Jessel, T. M. (1991). Principles of neural science. London: Prentice-Hall.

Kano, M., \& Fukudo, S. (2013). The alexithymic brain: the neural pathways linking alexithymia to physical disorders, Biopsychosocial Medicine, 7, 1-9.

Kano, M., Fukudo, S., \& Gyoba, J. (2003). Specific brain processing of facial expressions in people with alexithymia: An h-sub-2-sub (1-sup- 5) 0-PET study. Brain, 126, 14741484. 
Kong, F., Zhen, Z., Li, J., Huang, L., Wang, X., Song, Y., \& Liu, J. (2014). Sex-related neuroanatomical basis of emotion regulation ability. Plos One, 9(5), e97071.

Koven, N. S. \& Thomas, W. (2010). Mapping facets of alexithymia to executive dysfunction in daily life. Personality and Individual Differences, 49, 24 - 28.

Kubota, M., Miyata, J., Hirao, K., Fujiwara, H., Kawada, R., \& Fujimoto, S., Tanaka, Y., Sasamoto, A., Sawamoto, N., Fukuyama, H., Takahashi, H., \& Murai, T. (2011). Alexithymia and regional gray matter alterations in schizophrenia. Neuroscience Research, 70, 206-213.

Kubota, M., Miyata, J., Sasamoto, A., Kawada, R., Fujimito, S., Tanak, Y., Sawamoto, N., Fukuyama, H., Takahashi, H., \& Murai, T. (2012). Alexithymia and reduced white matter integrity in schizophrenia: a diffusion tensor imaging study on impaired emotional selfawareness. Schizophrenia Research, 141, 137-143.

Kugel, H., Eichmann, M., Dannlowski, U., Ohrmann, P., Bauer, J., Arolt, V., Heindel, W., \& Suslow, T. (2008). Alexithymic features and automatic amygdala reactivity to facial emotion. Neuroscience Letters, 435, 40 - 44.

Kuppens, P. (2010). From Appraisal to emotion. Emotion Review, 2 (2), 157-158.

Kuppens, P. (2013). Comment: Appraisal affords flexibility to emotion in more ways than one. Emotion Review, 5, 176-179. 
Lamberty, G. J., \& Holt, C. S. (1995). Evidence for a verbal deficit in alexithymia. The Journal of Neuropsychiatry and Clinical Neurosciences, 7, 320-324.

Lander, G. C., Lutz-Zois, C. J., Rye, M. S., \& Goodnight, J. A. (2012). The differential association between alexithymia and primary versus secondary psychopathy. Personality and Individual Difference, 52, 45 - 50.

Lane, R. D., Ahern, G. L., Schwartz, G. E., \& Kaszniak, A. W. (1997). Is alexythymia the emotional equivalent of blindsight? Biological Psychiatry, 42, 834 - 844.

Lane, R. D., Reiman, E. M., Axelrod, B., Yun, L. S., Holmes, A., \& Schwartz, G. E. (1998). Neural correlates of levels of emotional awareness: Evidence of an interaction between emotion and attention in the anterior cingulate cortex. Journal of Cognitive Neuroscience, 10, 525 - 535.

Larsen, J. K., Brand, N., Bermond, B., \& Hijman, R. (2003). Cognitive and emotional characteristics of alexithymia. A review of neurobiological studies. Journal of Psychosomatic Research, 54, 533-541.

Lazarus, R. S. (1991). Emotion and adaptation. New York: Oxford University Press.

Leweke, F., Stark, R., Milch, W., Kurth, R., Schienle, A., Kirsch, P., Stingl, M., Reimer, C., Vaitl, D. (2004). Patterns of neuronal activity related to emotional stimulation in alexithymia. Psychotherapie Psychosomatik Medizinische Psychologie, 54, 437- 444. 
Lysaker, P. H., Dimaggio, G., Buck, K. D., Carcione, A., \& Nicolò, G. (2007). Metacognition within narratives of schizophrenia: associations with multiple domains of neurocognition. Schizophrenia Research, 93, 278-287.

Lysaker, P. H., Gumley, A., Brüne, M., Vanheule, S., Buck, K. D., \& Dimaggio, G. (2011). Deficits in the ability to recognize one's own affects and those of others: associations with neurocognition, symptoms and sexual trauma among persons with schizophrenia spectrum disorders. Consciousness and Cognition, 20, 1183-1192.

Malloy, P., \& Duffy, J. (1994). The frontal lobes in neuropsychiatric disorders. In: Boller F, Grafman J, editors. Handbook of neuropsychology, vol. 9. Amsterdam, the Netherlands: Elsevier, 1994. pp. $203-32$.

Mandal, M. K., Borod, J. C., Asthana, H. S., Mohanty, A., Mohanty, S., \& Koff, E. (1999). Effects of lesion variables and emotion type on the perception of facial emotion. The Journal of Nervous and Mental Risease, 187, 603- 609.

Mattila, A. K., Salminen, J. K., Nummi, T., \& Joukamaa, M. (2006). Age is strongly associated with alexithymia in the general population. Journal of psychosomatic Research, 61, 629-635.

Mehu, M., \& Scherer, K. (2015). The Appraisal Bias Model of Cognitive Vulnerability to Depression. Emotion Review, 7(3), 272-279. 
Milner, B. (1963). Effects of different brain lesions on card sorting. Archives of Neurology, 9, $100-110$.

Moors, A., Ellsworth, C. Ph., Scherer, K. R., \& Frijda, N. H. (2013). Appraisal Theories of Emotion: State of the Art and Future Development. Emotion Review, 5 (2), 119-124.

Moriguchi, Y., Ohnishi, T., Decety, J., Hirakata, M., Maeda, M., Matsuda, H., \& Komaki, G. (2009). The human mirror neuron system in a population with deficient self-awareness: An fMRI study in alexithymia. Human Brain Mapping, 30 (7), 2063 - 2076.

Mul, C. L., Stagg, S. D., Herbelin, B., \& Aspell, J. E. (2018). The Feeling of Me Feeling for You: Interoception, Alexithymia and Empathy in Autism. Journal of Autism and Developmental Disorders, 48, 2953 - 2967.

Murphy, J., Brewer, R., Hobson, H., Catmure, C., \& Bird, G. (2018). Is alexithymia characterised by impaired interoception? Further evidence, the importance of control variables, and the problems with the Heartbeat Counting Task. Biological Psychology, $136,189-197$.

Murphy, J., Catmur, C., \& Bird, G. (2017). Alexithymia is associated with a multidomain, multidimensional failure of interoception: Evidence from novel tests. Journal of Experimental Psychology. General, 147(3), 398-408.

Nelson, H. E. (1976). A modified card sorting test sensitive to frontal lobe defects. Cortex, 12, 313-324. 
Nerissa, S. P. H., Wong, M. M. C., \& Lee, T. M. C. (2016). Neural connectivity of alexithymia: Specific association with major depressive disorder. Journal of Affective Disorders, 193, 362-372.

Nichelli, P. (1996). I disturbi spaziali e visuo-immaginativi. In G. Denes \& L. Pizzamiglio (Eds.), Manuale di neuropsicologia (pp. 609- 638). Bologna: Zanichelli.

Norman, D. A., \& Shallice, T. (1986). Attention to action: Willed and automatic control of behaviour. In R. J. Davidson, G. E. Schwartz, \& D. Shapiro (Eds.), Consciousness and self-regulation: Advances in research and theory (pp. 1-18). New York: Plenum.

Onor, M., Trevisiol, M., Spano, M., Aguglia, E., \& Paradiso, S. (2010). Alexithymia and aging: A neuropsychological perspective. The Journal of Nervous and Mental Disease, $198,891-895$.

Owen, A. M., Downes, J. J., Sahakian, B. J., Polkey, C. E., \& Robbins, T. W. (1990). Planning and spatial working memory following frontal lobe lesions in man. Neuropsychologia, 28, 1021- 1034.

Papageorgiou, C., \& Wells, A. (2004). Depressive rumination: Nature, theory and treatment. John Wiley \& Sons Ltd, (Eds.). Chichester, UK. 
Paradiso, S., Vaidya, J. G., McCormick, L. M., Jones, A., \& Robinson, R. G. (2008). Aging and alexithymia: Association with reduced right rostral cingulate volume. American Journal of Geriatric Psychiatry, 16(9), 760 - 769.

Parker, J. D. A., Bagby, R. M., \& Taylor; G. J. (1991). Alexithymia and depression: distinct or overlapping constructs? Comprehensive Psychiatry, 32 (5), 387 - 394.

Parker, J.D.A., Keightley, M.L., Smith, C.T., \&Taylor, G.J. (1999). Interhemispheric transfer deficit in alexithymia:An experimental study. Psychosomatic Medicine, 61, 464 - 468.

Parling, T., Mortazavi, M., \& Ghaderi, A. (2010). Alexithymia and emotional awareness in anorexia nervosa: time for a shift in the measurement of the concept? Eating Behaviors, $11,205-210$.

Phan, L. P., Wager, T., Taylor, S. F., \& Liberzon, I. (2002). Functional neuroanatomy of emotion: A meta-analysis of emotion activation studies in PET and fMRI. Neuroimage, $16,331-348$.

Phillips, M., Drevets, W., Rauch, S., \& Lane, R. (2003). Neurobiology of emotion perception I: The neural basis of normal emotion perception. Biological Psychiatry, 54(5), 504-14.

Pickup, G. J. (2008). Relationship between Theory of Mind and Executive Function in Schizophrenia: A Systematic Review. Psychopathology, 41, 206 - 213. 
Pollatos, O., \& Gramann, K. (2012). Attenuated modulation of brain activity accompanies emotion regulation deficits in alexithymia. Psychophysiology, 49 (5), 651-8.

Pouga, L., Berthoz, S., de Gelder, B., \& Grezes, J. (2010). Individual differences in socioaffective skills influence the neural bases of fear processing: the case of alexithymia. Human Brain Mapping, 31, 1469 - 1481.

Reitan, R. M., \& Wolfson, D. (1985). The Halstead-Reitan neuropsychological test battery: Therapy and clinical interpretation. Tucson, AZ: Neuropsychologycal Press.

Reker, M., Ohrmann, P., Rauch, A. V., Kugel, H., Bauer, J., Dannlowski, U., Arolt, V., Heindel, W., \& Suslow, T. (2010). Individual differences in alexithymia and brain response to masked emotion faces. Cortex, 46, 658-667.

Ricciardi, L., Demartini, B., Fotopoulou, A., \& Edwards, M.G. (2015). Alexithymia in Neurological Disease: A Review. Journal of Neuropsychiatry and Clinical Neuroscience, 27 (3), 179-187

Robinson, M. S., \& Alloy, L. B. (2003). Negative cognitive styles and stress-reactive rumination interact to predict depression: A prospective study. Cognitive Therapy and Research, 27, 275-291.

Rolls, E. T. (1995). A theory of emotion and consciousness and its application to understanding the neural basis of emotion. In M. S. Gazzaniga (Ed.), The cognitive neurosciences. Cambridge, MA: MIT Press. 
Rorden, C.,\&Brett, M. (2000). Stereotaxic display of brain lesions. Behavioral Neurology, 12, 191-200.

Roseman, I. J., \& Smith, C. A. (2001). Appraisal theory: Overview, assumptions, varieties, controversies. In K. R. Scherer \& A. Schorr (Eds.), Appraisal processes in emotion: Theory, methods, research (pp. 3-19). London, UK: Oxford University Press.

Rossi, A., F., Pessoa, L., Desimone, R., \& Ungerleider, L. G. (2009). The prefrontal cortex and the executive control of attention. Experimental Brain Research, 192 (3), 489 497.

Roth, R. M., Isquith, P. K., \& Gioia, G. A. (2005). Behavior rating inventory of executive function-adult version. Lutz, FL: Psychological Assessment Resources.

Santorelli, G. D. \& Ready, R. E. (2015). Alexithymia and Executive Function in Younger and Older Adults. The clinical Neuropsychologist, 29 (7), 938-955.

Scherer, K. R. (1984). On the nature and function of emotion: A component process approach. In P. Ekman (Ed.), Approaches to emotion (pp. 293-317). Hillsdale, NJ: Lawrence Erlbaum Associates.

Scherer, K. R. (2001). Appraisal considered as a process of multilevel sequential checking. In A. Schorr \& T. Johnstone (Eds.), Appraisal process in emotion: Theory, method, research (pp. 92-120). London, UK: Oxford University Press. 
Scherer, K. R. (2009). The dynamic architecture of emotion: Evidence for the component process model. Cognition and Emotion, 23, 1307-1351.

Shallice, T. (1988). From neuropsychology to mental structure. Cambridge, UK: Cambridge University Press.

Shallice, T., \& Burgess, P. W. (1998). Domain of supervisory processes and the temporal organization. In A. C. Roberts, T. W., Robbins, L., Weiskrantz (Eds.), The frontal cortex (pp. 22-35). Oxford: Oxford University Press.

Shallice, T., \& Burgess, P.W. (1991). Deficits in strategy application following frontal lobe damage in man. Brain, 114, 727-741.

Sifneos, P. E. (1973). The prevalence of "alexithymic" characteristics in psychosomatic patients. Psychotherapy and Psychosomatics, 22, 255 - 262.

Sifneos, P. E., Apfel-Savitz, R., \& Frankel, F. H. (1977). The phenomenon of 'alexithymia'. Observations in neurotic and psychosomatic patients. Psychotherapy and Psychosomatics, 28(1-4), 47- 57.

Stroop, J. R. (1935). Studies of interference in serial verbal reactions. Journal of Experimental Psychology, 18, 643-662. 
Sturm, V. E., \& Levenson, R. W. (2011). Alexithymia in neurodegenerative disease. Neurocase, 17, 242 - 250.

Stuss, D. (2011). Functions of the Frontal Lobes: Relation to Executive Functions. Journal of the International Neuropsychological Society, 17, 759 - 765.

Stuss, D. T., \& Benson, D. F. (1986). The frontal lobes. New York: Raven Press.

Stuss, D. T., Alexander, M. P., Shallice, T., Picton, T. W., Binns, M. A., Macdonald, R., Borowiec, A., Katz, D. I. (2005). Multiple frontal systems controlling response speed. Neuropsychologia, 43(3), 396 - 417.

Stuss, D. T., Shallice, T., Alexander, M. P., \& Picton, T.W. (1995). A multidisciplinary approach to anterior attentional functions. Annals of the New York Academy of Sciences, 769, $191-209$.

Suslow, T., \& Donges, U. S. (2017). Alexithymia Components Are Differentially Related to Explicit Negative Affect But Not Associated with Explicit Positive Affect or Implicit Affectivity. Frontiers in Psychology, 8, 1758.

Talairach, J., \& Tournoux, P. (1988). Co-planar stereotaxic atlas of the human brain: Three dimensional proportional system: An approach to medical cerebral imaging. Stuttgart, New York, NY: G. Thieme Medical Publishers. 
Taylor, G. J, Bagby, R. M. (1988).Measurement of alexithymia: recommendations for clinical practice and future research. Psychiatr Clin North Am,11, 351 -64

Taylor, G. J., Bagby, R. M., \& Parker, J. D. A. (1997). Disorders of Affect Regulation: Alexithymia in Medical and Psychiatric Illness. Cambridge: Cambridge University Press.

Thorberg, F. A., Young, R. M., Sullivan, K. A., \& Lyvers, M. (2009). Alexithymia and alcohol use disorders: A critical review. Addictive Behaviors, 34(3), 237-245.

Troisi, E., Peppe, A., Pierantozzi, M., Matteis, M., Vernieri, F., Stanzione, P., Silvestrini, M., \& Caltagirone, C. (2002). Emotional processing in Parkinson's disease. A study using functional transcranial Doppler sonography. Journal of Neurology, 249, 993- 1000.

Tzourio-Mazoyer, N., Landeau, B., Papathanassiou, D., Crivello, F., Etard, O., Delcroix, N., Mazoyer, B., \& Joliot, M. (2002). Automated anatomical labeling of activations in SPM using a macroscopic anatomical parcellation of the MNI MRI single subject brain. NeuroImage, 15, 273-289.

Van der Velde, J., Servaas, M. N., Goerlich, K. S., Bruggeman, R., Horton, P., Costafreda, S. G. \& Aleman, A. (2013). Neural correlates of alexithymia: a meta-analysis of emotion processing studies, Neuroscience and Biobehavioral Reviews, 37 (8), 17741785. 
Van der Velde, J., Van Tol, M. J., Goerlich-Dobre, K. S., Gromann, P. M., Swart, M., de Haan, L., Wiersma, D., Bruggeman, R., Krabbendam, L. \& Aleman, A. (2014). Dissociable morphometric profiles of the affective and cognitive dimensions of alexithymia. Cortex, 54, 190-199.

Walsh, K.W. (1978). Neuropsychology. New York: Churchill Livingstone/Longman.

Warrington, E.K. \& Rabin, P. (1970). Perceptual matching in patients with cerebral lesions. Neuropsychologia, 8, 175-187.

Williams, C. \& Wood, R. L. (2010). Alexithymia and emotional empathy following traumatic brain injury. Journal of Clinical and Experimental Neuropsychology, 32, 259-267.

Williams, K. R., Galas, J., Light, D., Pepper, C., Ryan, C., Kleinmann, A. E., Burright, R., Donovick, P. (2001). Head injury and alexithymia: Implications for family practice care. Brain Injury, 15, 349 - 356.

Wilson, B. A., Alderman, N., Burgess, P., Emslie, H., \& Evans, J. J. (1996). Behavioural assessment of the dysexecutive syndrome (BADS). Bury St Edmunds, UK, Suffolk: Thames Valley Test Company.

Wingbermühle, E., Theunissen, H., Verhoeven, W. M., Kessels, R. P., \& Egger, J. I. (2012). The neurocognition of alexithymia: evidence from neuropsychological and neuroimaging studies. Acta Neuropsychiatrica, 24, 67-80. 
Wood, R. L., \& Williams, C. (2007). Neuropsychological correlates of organic alexithymia. Journal of International Neuropsychological Society, 13 (3), 471-479.

Xiong-Zhao, Z., Xiao-Yan, W. \& Ying, H. (2006) A comparative study of Wisconsin Card Sorting Test in individuals with different degrees of alexithymia. Chinese Journal of Clinical Psychology 14(2): 132-133.

Xua, P., Opmeer, E. M., van Tolb, M. J., Goerlichd, K. S., \& Alemana, A. (2018). Structure of the alexithymic brain: A parametric coordinate-based metaanalysis. Neuroscience and Biobehavioral Reviews, 87, 50-55.

Yuan, J., Luo, Y., Yan, J. H., Meng, X., Yu, F., \& Li, H. (2009). Neural correlates of the females' susceptibility to negative emotions: an insight into gender-related prevalence of affective disturbances. Human Brain Mapping, 30, 3676 - 3686.

Yuan, P., \& Raz, N. (2014). Prefrontal Cortex and Executive Functions in Healthy Adults: A Meta-Analysis of Structural Neuroimaging Studies. Neuroscience and Biobehavioral Reviews, 0, 180-192.

Zhang, L., Zhu, C., Y., R., Cao, Z., Tian, Y., Yang, P., Hu, P.,\& Wang, K. (2011). Impairment of conflict processing in alexithymic individuals. Neuroscience Letters, 504 (3), 261-264. 
Zhu, X. Z., Wang, X. Y., \& Huang, Y. (2006). A comparative study of Wisconsin Card Sorting Test in individuals with different degrees of alexithymia. Chinese Journal of Clinical Psychology, 14, 131-133. 


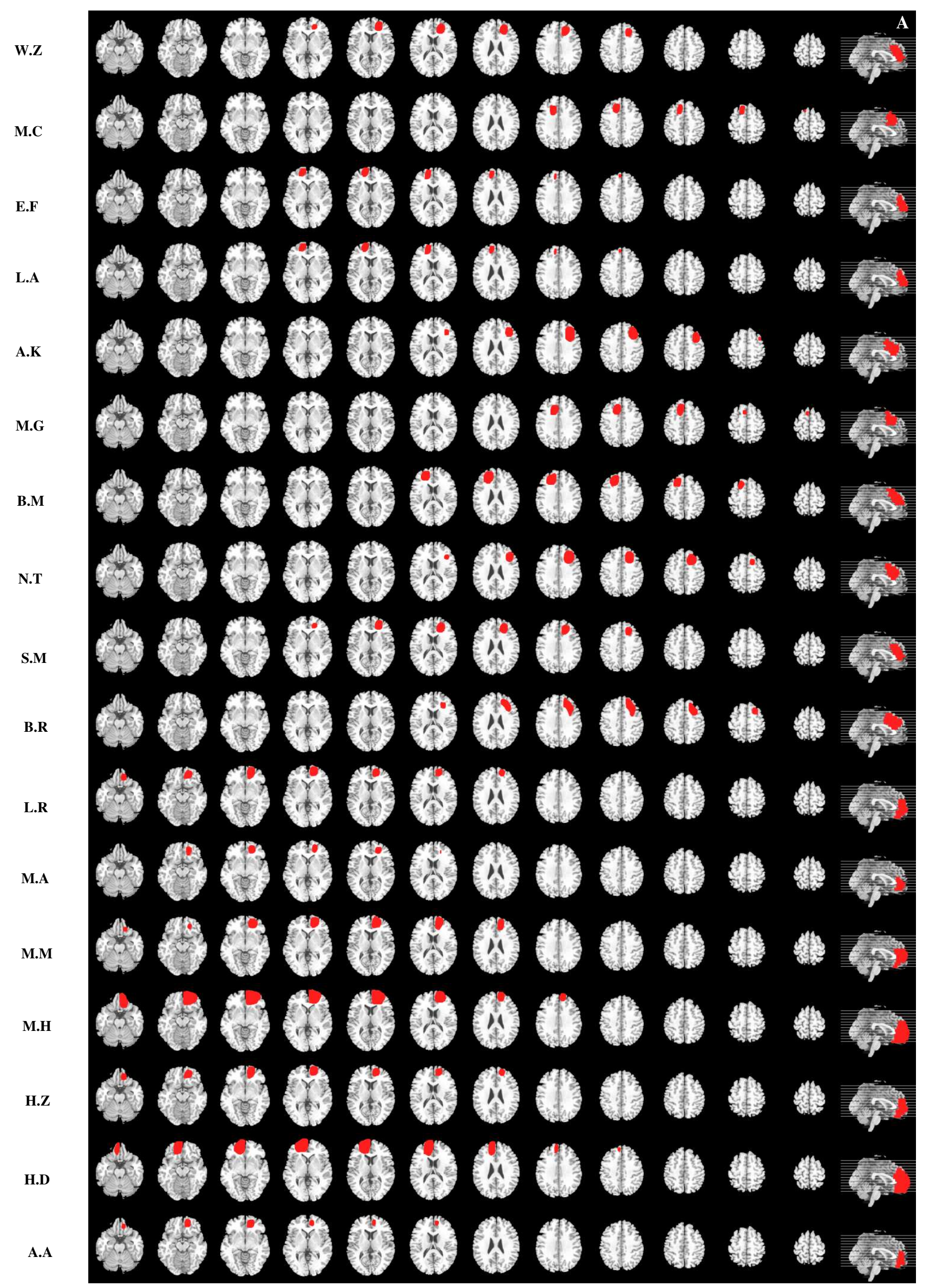


O.B

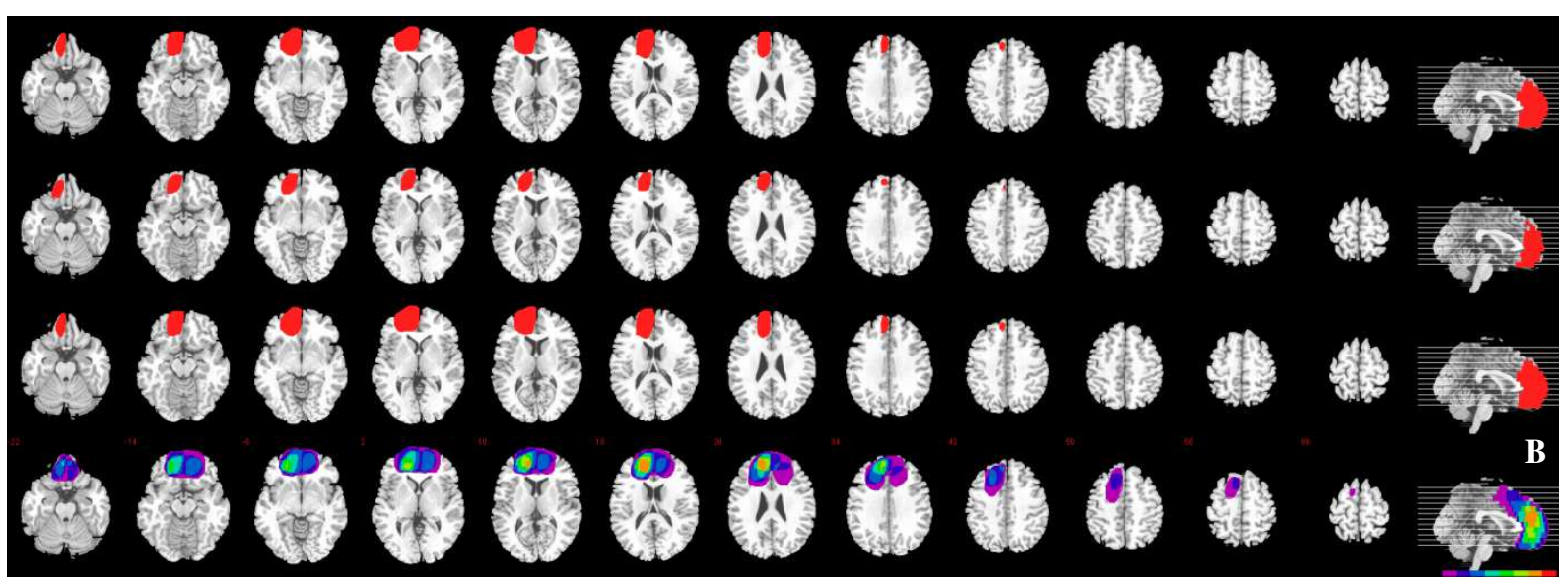

Fig 1: (A) Lesion location of each patient with prefrontal cortex damage; (B) Lesion overlay of 20 patients with prefrontal cortex damage. 


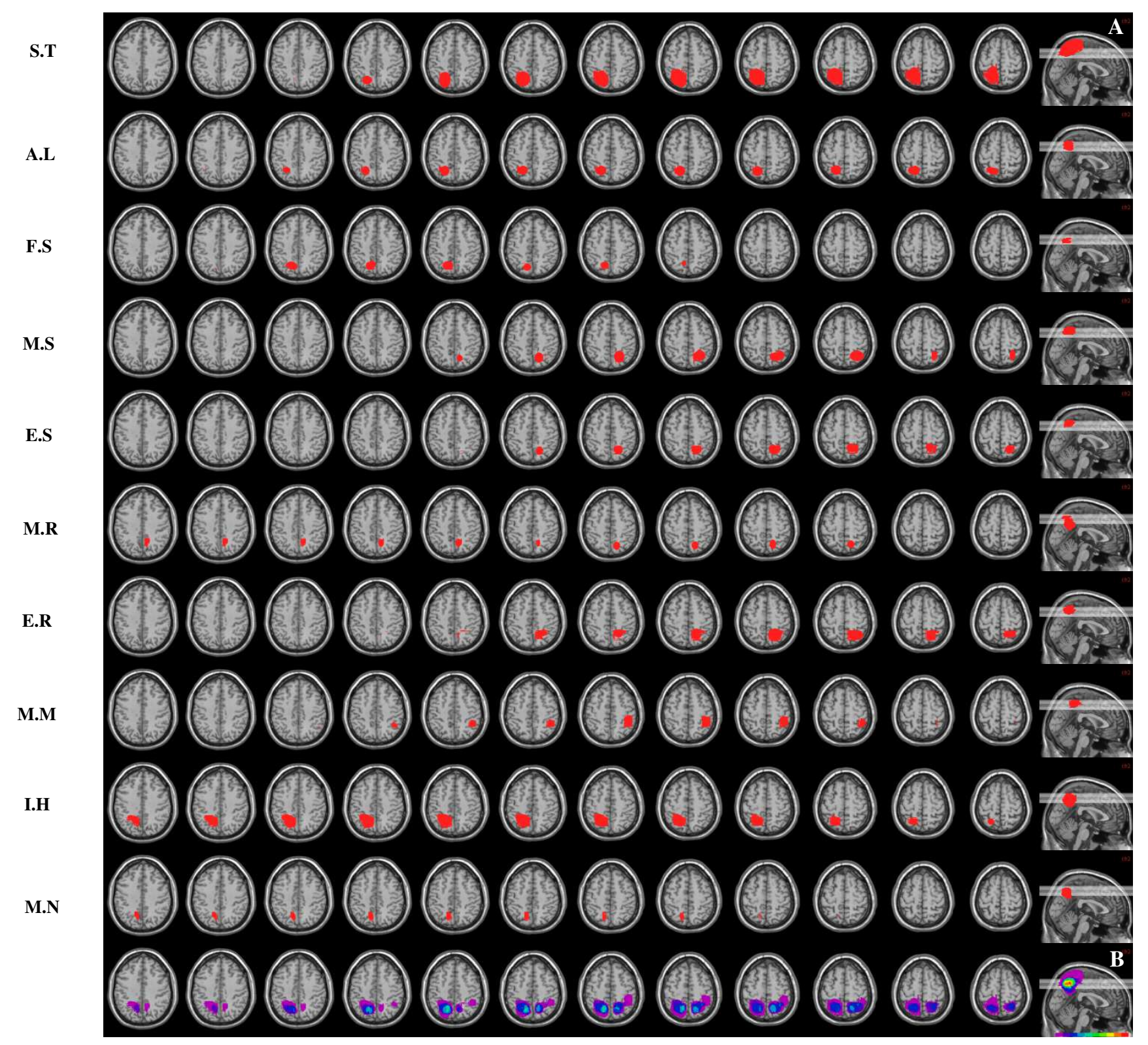

Figure 2: (A) Lesion location of each patient with parietal cortex damage; (B) Lesion overlay of 10 patients with parietal cortex damage. 


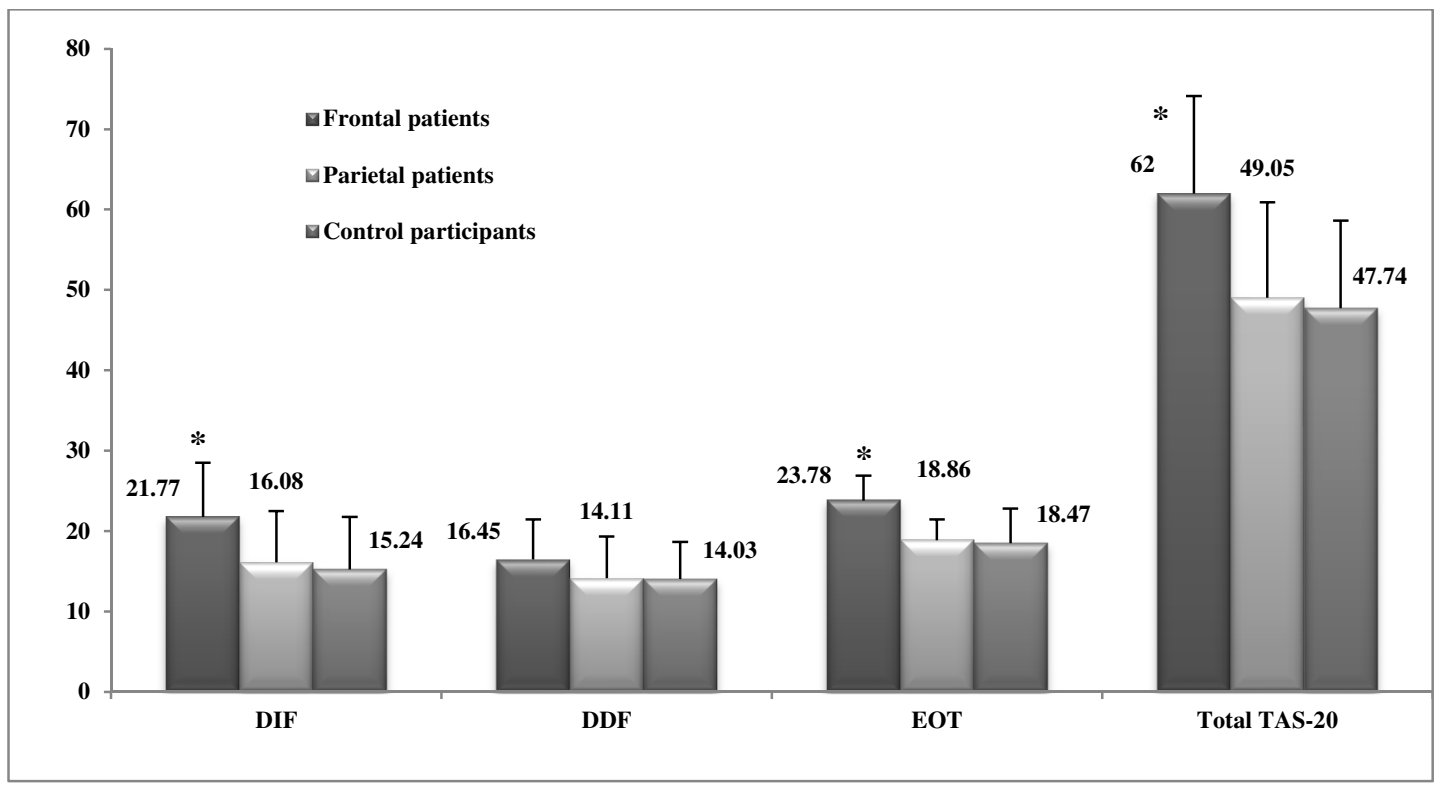

Figure 3: performance of fontal patients, parietal patients and control participants on the three facets of TAS-20 


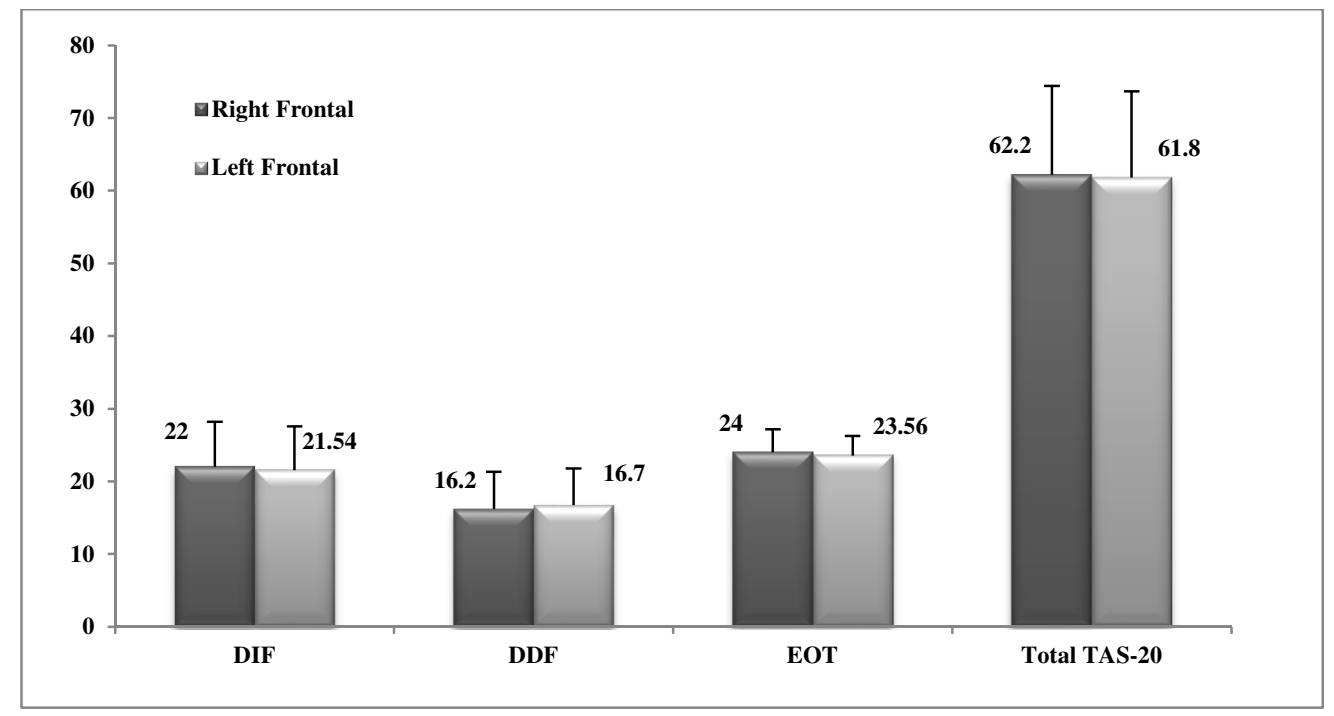

Figure 4: performance of Right and Left fontal patients on the three facets of TAS-20 


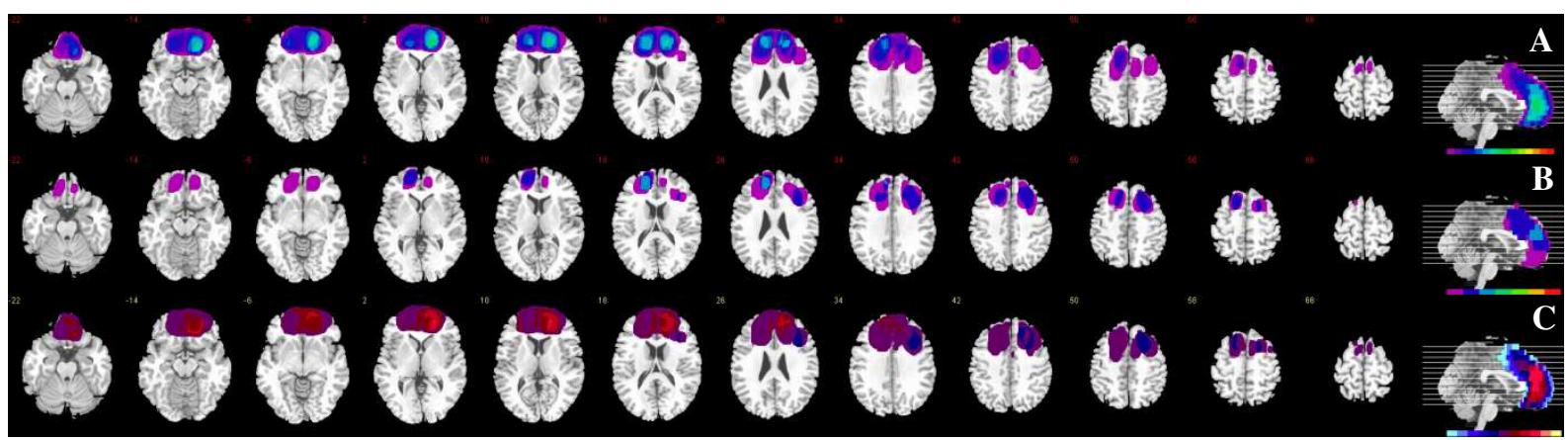

Figure 5: (A) Lesion overlay of alexithymic frontal patients group $(\mathrm{N}=10)$. The colors indicate the number of frontal patients with same lesion location (purple $=1$ to red $=10$ ). $(B)$ Lesion overlay of non-alexithymic frontal patients group $(N=10)$. The colors indicate the number of frontal patients with same lesion location (purple=1 to red $=10$ ). (C) Subtraction of lesion overlay of frontal patients (A) minus (B). The percentage of overlapping lesion after subtraction was illustrated by different colors which code increasing frequencies, from dark red $($ difference $=1-20 \%)$ to white yellow $($ difference $=81-100 \%)$. The color from purple $($ difference $=-1 \%$ to $20 \%$ ) to light blue (difference $=\mathbf{- 8 1} \%$ to $-\mathbf{- 1 0 0} \%$ ) showed cerebral regions commonly damaged but not involved alexithymia deficit. 
Table 1: Main clinical characteristics of the frontal patients.

\begin{tabular}{|c|c|c|c|c|c|c|c|c|c|}
\hline Patients & Gender & Age & Etiology & $\begin{array}{c}\text { Lesion } \\
\text { Side }\end{array}$ & Lesion location & $\begin{array}{c}\begin{array}{c}\text { Time since } \\
\text { lesion } \\
\text { (days) }\end{array} \\
\end{array}$ & $\begin{array}{c}\text { Glasgow } \\
\text { Coma Scale }\end{array}$ & $\begin{array}{c}\text { Mini Mental } \\
\text { State } \\
\text { Examination } \\
\end{array}$ & Medication \\
\hline W.Z & $\mathbf{F}$ & 54 & Oligodendroglioma & Left & DL & 132 & 15 & 28 & Sodium valproate \\
\hline L.R & $\mathbf{H}$ & 23 & Hematoma & Left & VM & 162 & 15 & 29 & None \\
\hline M.C & $\mathbf{H}$ & 54 & Oligodendroglioma & Left & DL & 185 & 15 & 28 & Sodium valproate \\
\hline M.A & $\mathbf{H}$ & 19 & $\begin{array}{c}\text { Haemorrhagic } \\
\text { contusion }\end{array}$ & Right & VM & 158 & 15 & 29 & None \\
\hline M.M & $\mathbf{F}$ & 32 & Oligoastrocytoma & Right & VM & 120 & 15 & 28 & Sodium valproate \\
\hline E.F & $\mathbf{H}$ & 39 & $\begin{array}{l}\text { Haemorrhagic } \\
\text { contusion }\end{array}$ & Left & DL & 147 & 15 & 29 & None \\
\hline L.A & $\mathbf{H}$ & 43 & $\begin{array}{c}\text { Haemorrhagic } \\
\text { contusion }\end{array}$ & Left & DL & 165 & 14 & 29 & None \\
\hline М.H & $\mathbf{H}$ & 56 & Meningioma & Right & VM & 196 & 15 & 28 & Sodium valproate \\
\hline H.Z & $\mathbf{H}$ & 57 & Hematoma & Right & VM & 300 & 15 & 28 & None \\
\hline A.K & $\mathbf{H}$ & 40 & Oligodendroglioma & Right & DL & 143 & 15 & 29 & Sodium valproate \\
\hline M.G & $\mathbf{H}$ & 59 & Meningioma & Right & DL & 149 & 15 & 28 & Sodium valproate \\
\hline B.M & $\mathbf{H}$ & 49 & $\begin{array}{l}\text { Haemorrhagic } \\
\text { contusion }\end{array}$ & Left & DL & 208 & 14 & 29 & None \\
\hline N.T & $\mathbf{H}$ & 35 & Cavernoma & Right & DL & 169 & 15 & 29 & Sodium valproate \\
\hline H.D & $\mathbf{H}$ & 21 & $\begin{array}{l}\text { Haemorrhagic } \\
\text { contusion }\end{array}$ & Left & VM & 124 & 15 & 29 & None \\
\hline A.A & $\mathbf{H}$ & 24 & $\begin{array}{l}\text { Haemorrhagic } \\
\text { contusion }\end{array}$ & Right & VM & 158 & 14 & 29 & None \\
\hline S.M & $\mathbf{H}$ & 56 & Astrocytoma & Right & DL & 194 & 15 & 28 & Sodium valproate \\
\hline O.B & $\mathbf{F}$ & 54 & Meningioma & Left & VM & 183 & 15 & 28 & Sodium valproate \\
\hline B.R & $\mathbf{F}$ & 29 & Astrocytoma & Right & DL & 184 & 15 & 29 & Sodium valproate \\
\hline S.B & $\mathbf{H}$ & 30 & $\begin{array}{c}\text { Haemorrhagic } \\
\text { Contusion }\end{array}$ & Left & VM & 287 & 15 & 29 & None \\
\hline J.F & $\mathbf{H}$ & 51 & Oligoastrocytoma & Left & VM & 151 & 15 & 29 & Sodium valproate \\
\hline
\end{tabular}

DL: dorsolateral; VM: ventromedial 
Table 2: Description of lesion volume and anatomical structures damaged in frontal patients group

\begin{tabular}{|c|c|c|c|c|c|}
\hline Patients & Etiology & Lesion side & Lesion location & Lesion site & Lesion volume $\mathrm{cm}^{3}$ \\
\hline W.Z & Oligodendroglioma & Left & $\mathrm{DL}$ & SFG; MedSFG; MFG & 13.2 \\
\hline L.R & Hematoma & Left & VM & OrbSFG; OrbMFG; GR & 21 \\
\hline M.C & Oligodendroglioma & Left & DL & SFG; MedSFG; MFG; ACING; SMA & 18.7 \\
\hline M.A & Haemorrhagic contusion & Right & VM & OrbSFG; OrbMFG & 12.5 \\
\hline M.M & Oligoastrocytoma & Right & VM & OrbSFG; OrbMFG, OrbIFG; GR & 20.3 \\
\hline E.F & Haemorrhagic contusion & Left & D.L & SFG; MedSFG; MFG & 14.1 \\
\hline L.A & Haemorrhagic contusion & Left & D.L & SFG; MedSFG; MFG & 16.4 \\
\hline M.H & Meningioma & Right & VM & OrbSFG; OrbMFG; OrbIFG; GR & 54.4 \\
\hline H.Z & Hematoma & Right & VM & OrbSFG; OrbMFG; GR & 22.1 \\
\hline A.K & Oligodendroglioma & Right & DL & O-IFG; T-IFG; SFG; PRE; & 25.3 \\
\hline M.G & Meningioma & Right & DL & SFG; MedSFG; MFG; SMA & 17.3 \\
\hline B.M & Haemorrhagic contusion & Left & DL & SFG; MedSFG; MFG; T-IFG; O-IFG & 31.5 \\
\hline N.T & Cavernoma & Right & $\mathrm{DL}$ & SFG; MFG; T-IFG; O-IFG; SMA & 27.7 \\
\hline H.D & Haemorrhagic contusion & Left & VM & OrbMFG ; OrbIFG ; GR & 10.7 \\
\hline A.A & Haemorrhagic contusion & Right & VM & OrbSFG; OrbMFG; OrbIFG; GR & 12.5 \\
\hline S.M & Astrocytoma & Right & DL & SFG; MFG & 23.3 \\
\hline O.B & Meningioma & Left & VM & OrbSFG; OrbMFG; OrbIFG; GR & 41.8 \\
\hline B.R & Astrocytoma & Right & DL & SFG; MFG; PRE & 30.4 \\
\hline S.B & Haemorrhagic contusion & Left & VM & OrbSFG; OrbMFG & 11 \\
\hline J.F & Oligoastrocytoma & Left & VM & OrbSFG; OrbMFG, OrbIFG & 22.1 \\
\hline
\end{tabular}

Superior frontal gyrus (SFG); Medial superior frontal gyrus (MedSFG); Middle frontal gyrus (MFG); Operculum inferior frontal gyrus (O-IFG); Triangular inferior frontal gyrus (T-IFG); Orbital superior frontal gyrus (OrbSFG); Orbital middle frontal gyrus (OrbMFG); Orbital inferior frotal gyrus (OrbIFG); Anterior cingulate gyrus (ACING); Gyrus rectus (GR); Supplementary motor area (SMA); Precentral gyrus (PRE) 
Table 3: Main clinical characteristics of the parietal patients.

\begin{tabular}{|c|c|c|c|c|c|c|c|c|}
\hline Patients & Gender & Age & Etiology & $\begin{array}{l}\text { Lesion } \\
\text { Side }\end{array}$ & $\begin{array}{c}\text { Time since } \\
\text { lesion (days) }\end{array}$ & $\begin{array}{c}\text { Glasgow } \\
\text { Coma Scale }\end{array}$ & $\begin{array}{l}\text { Mini Mental } \\
\text { State } \\
\text { Examination } \\
\end{array}$ & Medication \\
\hline S.T & $\mathbf{F}$ & 35 & Meningioma & Left & 156 & 15 & 29 & Sodium valproate \\
\hline A.L & $\mathbf{H}$ & 28 & Cavernoma & Left & 186 & 15 & 30 & Sodium valproate \\
\hline F.S & $\mathbf{H}$ & 47 & Hematoma & Left & 153 & 15 & 29 & None \\
\hline M.S & $\mathbf{F}$ & 49 & Cavernoma & Right & 148 & 15 & 29 & Sodium valproate \\
\hline E.S & $\mathbf{H}$ & 37 & Astrocytoma & Right & 146 & 15 & 29 & Sodium valproate \\
\hline M.R & $\mathbf{H}$ & 42 & Anaplastic astrocytoma & Right & 185 & 15 & 29 & Sodium valproate \\
\hline E.R & $\mathbf{H}$ & 34 & Astrocytoma & Right & 181 & 15 & 30 & Sodium valproate \\
\hline M.M & $\mathbf{H}$ & 38 & Oligodendroglioma & Right & 154 & 15 & 30 & Sodium valproate \\
\hline I.H & $\mathbf{H}$ & 39 & Astrocytoma & Left & 147 & 15 & 29 & Sodium valproate \\
\hline M.N & $\mathbf{H}$ & 44 & Oligodendroglioma & Left & 138 & 15 & 29 & Sodium valproate \\
\hline
\end{tabular}


Table 4: Description of lesion aetiologies, lesion volume and anatomical structures damaged in parietal patients

\begin{tabular}{|c|c|c|c|c|}
\hline Patients & Etiology & $\begin{array}{l}\text { Lesion } \\
\text { Side }\end{array}$ & Lesion site & $\begin{array}{l}\text { Lesion volume } \\
\text { cm }^{3}\end{array}$ \\
\hline S.T & Meningioma & Left & $\begin{array}{c}\text { Post central gyrus; Superior parietal gyrus; Inferior parietal } \\
\text { gyrus; Precuneus }\end{array}$ & 28.2 \\
\hline \multirow[t]{2}{*}{ A.L } & Cavernoma & Left & & 8.7 \\
\hline & & & Superior parietal gyrus; Inferior parietal gyrus; Precuneus & \\
\hline F.S & Hematoma & Left & Superior parietal gyrus; Precuneus & 3.9 \\
\hline M.S & Cavernoma & Right & Superior parietal gyrus; Precuneus & 7.1 \\
\hline E.S & Astrocytoma & Right & Superior parietal gyrus; Precuneus & 6.1 \\
\hline M.R & $\begin{array}{l}\text { Anaplastic } \\
\text { astrocytoma }\end{array}$ & Right & Superior parietal gyrus; Precuneus & 6.2 \\
\hline E.R & Astrocytoma & Right & Superior parietal gyrus; Inferior parietal gyrus; Precuneus & 9.4 \\
\hline M.M & Oligodendroglioma & Right & Superior parietal gyrus; Inferior parietal gyrus & 5 \\
\hline I.H & Astrocytoma & Left & Superior parietal gyrus; Inferior parietal gyrus; Precuneus & 17.4 \\
\hline M.N & Oligodendroglioma & Left & Superior parietal gyrus; Precuneus & 3.6 \\
\hline
\end{tabular}


Table 5: Comparison of frontal patients with parietal patients and control participants to different executive tasks.

\begin{tabular}{|c|c|c|c|c|c|c|c|c|c|c|}
\hline Test & $\begin{array}{c}\mathrm{CP} \\
\mathrm{N}=34\end{array}$ & $\begin{array}{c}\mathrm{F} \\
\mathrm{N}=20\end{array}$ & $\begin{array}{c}P \\
N=10\end{array}$ & $\begin{array}{c}\text { All subgroup } \\
\text { P Level }\end{array}$ & CP.vs F & CP vs P & F vs P & $\begin{array}{c}\text { RF } \\
N=10\end{array}$ & $\begin{array}{c}\text { LF } \\
\mathrm{N}=10\end{array}$ & RF vs LF \\
\hline \multicolumn{11}{|l|}{ Executive tasks } \\
\hline \multicolumn{11}{|l|}{ Stroop } \\
\hline Inhibition time & $109.06(15.38)$ & $132.3(41.58)$ & $118.34(19.2)$ & $\mathrm{H}=8.41 ; p<.001$ & $*$ & ns & $*$ & $132.7(42.32)$ & $131.9(40.84)$ & ns \\
\hline Number of errors & $0.82(0.78)$ & $3.8(3.6)$ & $1.12(0.43)$ & $H=8.68 ; p<.001$ & $*$ & ns & $*$ & $3.72(3.5)$ & $3.88(3.7)$ & ns \\
\hline \multicolumn{11}{|l|}{ Hayling } \\
\hline B-A & $1.49(0.65)$ & $2.34(0.66)$ & $1.72(0.54)$ & $H=12.03 ; p<.001$ & $*$ & ns & $*$ & $2.28(0.62)$ & $2.4(0.7)$ & ns \\
\hline Shallice error scores & $3.44(2.06)$ & $8.4(4.78)$ & $6.34(3.67)$ & $H=23.13 ; p<.001$ & $*$ & $*$ & * & $8(4.66)$ & $8.8(4.9)$ & ns \\
\hline \multicolumn{11}{|l|}{ Verbal Fluency } \\
\hline Semantic: Number of word (animals) & $22.79(3.92)$ & $17.2(5.26)$ & $20.22(3.78)$ & $H=9.83 ; p<.001$ & $*$ & ns & $*$ & $16.9(5.12)$ & $17.5(5.4)$ & ns \\
\hline Phonemic: Number of word (p) & $15.88(2.85)$ & $9.6(3.36)$ & $14.11(2.7)$ & $H=13.16 ; p<.001$ & $*$ & ns & $*$ & $9.2(3.22)$ & $10(3.5)$ & ns \\
\hline \multicolumn{11}{|l|}{ MCST } \\
\hline Time in second & $179.62(41.58)$ & $269.2(88.14)$ & $188.44(44.23)$ & $H=21.39 ; p<.001$ & $*$ & ns & $*$ & $279(90.2)$ & $259.4(86.08)$ & ns \\
\hline Number of category & $5.70(0.21)$ & $4.6(1.7)$ & $5.4(0.32)$ & $H=23.97 ; p<.001$ & * & ns & * & $4.2(1.5)$ & $5(1.9)$ & ns \\
\hline Perseverative errors & $1.46(.12)$ & $4.88(6.28)$ & $1.85(1.4)$ & $H=42.12 ; p<.001$ & * & ns & * & $5.21(6.72)$ & $4.55(5.84)$ & ns \\
\hline Non perseverative errors & $2.79(1.7)$ & $12.18(9.47)$ & $4.02(1.9)$ & $H=18.5 ; p<.001$ & $*$ & ns & $*$ & $13.2(10.2)$ & $11.16(8.74)$ & ns \\
\hline \multicolumn{11}{|l|}{ Trail making test } \\
\hline Time in second B-A & $54.74(19.28)$ & $96.46(38.4)$ & $64.54(11.12)$ & $H=23.74 ; p<.001$ & $*$ & ns & $*$ & $100.4(40.3)$ & $92.52(36.5)$ & ns \\
\hline Number of errors & $0.32(0.04)$ & $1.34(0.9)$ & $0.3(0.07)$ & $H=11.1 ; p<.001$ & $*$ & ns & $*$ & $1.7(0.96)$ & $0.98(0.84)$ & ns \\
\hline \multicolumn{11}{|l|}{ Brixton } \\
\hline Number of errors & $3.35(1.72)$ & $12.9(6.6)$ & $4.4(1.48)$ & $\mathrm{H}=39.57 ; \mathbf{p}<.001$ & $*$ & ns & $*$ & $14.8(7.4)$ & $11(5.8)$ & ns \\
\hline Number of rule breaks & $0.7(0.84)$ & $2.36(1.2)$ & $1.99(0.74)$ & $H=.8 .67 ; p<.001$ & $*$ & $*$ & ns & $2.8(1.4)$ & $1.92(1)$ & ns \\
\hline \multicolumn{11}{|l|}{ Six Elements } \\
\hline Profil score & $3.97(0.17)$ & $2.44(0.84)$ & $2.86(0.84)$ & $H=35.14 ; p<.001$ & $*$ & $*$ & ns & $2.24(0.78)$ & $2.64(0.9)$ & ns \\
\hline Number of rules breaks & $0.03(0.17)$ & $1.46(1.23)$ & $1.2(0.77)$ & $H=27.24 ; p<.001$ & $*$ & $*$ & ns & $1.72(1.32)$ & $1.2(1.14)$ & ns \\
\hline \multicolumn{11}{|l|}{ Tower of London } \\
\hline Latency time & $3.4(0.49)$ & $4.87(1.46)$ & $3.6(.52)$ & $H=9.24 ; p<.001$ & $*$ & ns & $*$ & $5.34(1.6)$ & $4.4(1.32)$ & ns \\
\hline Total time & $19.41(3.72)$ & $25.87(7.78)$ & $21.06(3.88)$ & $\mathrm{H}=11.55 ;<.001$ & $*$ & ns & $*$ & $27.11(7.88)$ & $24.63(7.68)$ & ns \\
\hline Movement & $6.32(0.64)$ & $8.19(1.36)$ & $7.3(1.22)$ & $H=16.18 ; p<.001$ & $*$ & $*$ & ns & $9.45(1.56)$ & $6.93(1.16)$ & ns \\
\hline \multicolumn{11}{|l|}{ Digit Span } \\
\hline Forward span & $5.88(0.48)$ & $5.38(0.39)$ & $5(0.2)$ & $H=3.6 ; p=.17$ & ns & ns & ns & $5.34(0.4)$ & $5.42(0.38)$ & ns \\
\hline Backward span & $4.95(0.54)$ & $3.2(0.4)$ & $4.1(0.04)$ & $H=27.45 ; p<.001$ & $*$ & ns & $*$ & $3.3(0.42)$ & $3.1(0.38)$ & ns \\
\hline
\end{tabular}

( ): standard errors; * P<.01; CP: Control Participants; F: Frontal; P: Parietal; RF: Right frontal; LF: Left Frontal

Between groups comparison (normal controls vs frontal patients vs parietal patients) were performed with Kruskal-Wallis ANOVA. When Kruskal-Wallis

ANOVA were significant, these were followed by pairwise comparison using Mann-Whitney $\mathrm{U}$ tests after Bonferroni correction.

Between groups comparison (left frontal vs right frontal), with Mann-Whitney $U$ tests after Bonferroni correction 
Table 6: Correlation between executive tasks and TAS-20 for frontal patients, parietal patients and control participants

\begin{tabular}{|c|c|c|c|c|c|c|c|c|c|c|c|c|}
\hline & \multicolumn{4}{|c|}{ Control Participants } & \multicolumn{4}{|c|}{ Parietal Patients } & \multicolumn{4}{|c|}{ Frontal patients } \\
\hline & DIF & DDF & EOT & $\begin{array}{c}\text { Total } \\
\text { TAS-20 }\end{array}$ & DIF & DDF & EOT & $\begin{array}{c}\text { Total } \\
\text { TAS-20 }\end{array}$ & DIF & DDF & EOT & $\begin{array}{c}\text { Total } \\
\text { TAS-20 }\end{array}$ \\
\hline \multicolumn{13}{|l|}{ Stroop } \\
\hline Time in second & -- & -- & -- & -- & -- & -- & -- & -- & -- & -- & -- & -- \\
\hline Number of errors & -- & -- & -- & -- & -- & -- & -- & -- & -- & -- & -- & -- \\
\hline \multicolumn{13}{|l|}{ Hayling } \\
\hline B-A & $-.40 *$ & -- & -- & -- & -- & -- & -- & -- & -- & -- & -- & -- \\
\hline Shallice error scores & -- & -- & -- & -- & $.52 *$ & -- & -- & $.50 *$ & -- & -- & $.66^{*}$ & $.50 *$ \\
\hline \multicolumn{13}{|l|}{ Verbal Fluency } \\
\hline Semantic: Number of word (animals) & -- & -- & -- & -- & -- & -- & -- & -- & -- & -- & -- & -- \\
\hline Phonemic: Number of word (p) & $-.48 *$ & -- & -- & -- & -- & -- & -- & -- & $-.59 *$ & -- & -- & $-.49 *$ \\
\hline \multicolumn{13}{|l|}{ Modified Card Sorting Test } \\
\hline Time & -- & -- & -- & -- & -- & -- & -- & -- & -- & -- & -- & -- \\
\hline Completed Category & -- & -- & -- & -- & -- & -- & -- & -- & -- & -- & $-.71 *$ & $-.52 *$ \\
\hline Perseverative errors & -- & -- & -- & -- & -- & -- & -- & -- & $58 *$ & -- & $.67 *$ & $.50 *$ \\
\hline Non perseverative errors & $.48 *$ & -- & -- & $.47 *$ & $.50 *$ & -- & $.52 *$ & $.50 *$ & -- & -- & $.56 *$ & $.48^{*}$ \\
\hline Trail making test & & & & & -- & -- & & & -- & -- & & \\
\hline Time in second B-A & -- & -- & -- & -- & -- & -- & -- & -- & -- & -- & $.56 *$ & $.49 *$ \\
\hline Number of errors & -- & -- & -- & -- & -- & -- & -- & -- & -- & -- & -- & -- \\
\hline \multicolumn{13}{|l|}{ Brixton } \\
\hline Number of errors & -- & -- & -- & -- & -- & -- & -- & -- & -- & -- & -- & -- \\
\hline Number of rules breaks & -- & -- & -- & -- & -- & -- & -- & -- & -- & -- & -- & -- \\
\hline \multicolumn{13}{|l|}{ Tower of London } \\
\hline Latency time & -- & -- & -- & -- & -- & -- & -- & -- & -- & -- & -- & -- \\
\hline Total time & -- & -- & -- & -- & -- & -- & -- & -- & -- & -- & -- & -- \\
\hline Mouvements & -- & -- & -- & -- & -- & -- & -- & -- & -- & -- & -- & -- \\
\hline \multicolumn{13}{|l|}{ Six elements task } \\
\hline Profile score & -- & -- & -- & -- & -- & -- & -- & -- & -- & -- & -- & -- \\
\hline Number of rules breaks & $.47 *$ & $.46^{*}$ & -- & $.45^{*}$ & $.52 *$ & -- & -- & $.50 *$ & $.53 *$ & $.50 *$ & -- & $.50 *$ \\
\hline \multicolumn{13}{|l|}{ Digit span } \\
\hline Forward span & -- & -- & -- & -- & -- & -- & -- & -- & -- & -- & -- & -- \\
\hline Backward span & -- & -- & -- & -- & -- & -- & -- & -- & -- & -- & -- & -- \\
\hline
\end{tabular}

Correlation analysis after Bonferroni correction: * p<.001; (--) non-significant 